\title{
ANÁLISE ESTRATIGRÁFICAAPLICADAA PORÇÃO NORTE E NORDESTE DA BACIA BAURU (CRETÁCEO SUPERIOR)
}

\author{
ALESSANDRO BATEZELLI ${ }^{1}$, ANTONIO ROBERTO SAAD ${ }^{2}$, \\ JOSÉ ALEXANDRE DE JESUS PERINOTTO ${ }^{3}$ \& VICENTE JOSÉ FULFARO ${ }^{4}$
}

\begin{abstract}
Resumo A Bacia Bauru, entidade geotectônica gerada durante o Cretáceo Superior na porção sudeste da Placa Sul-americana, tem sido alvo de inúmeras pesquisas desde o final do Século XIX. Na porção norte e nordeste da bacia a maior parte dos estudos se concentra principalmente nos arredores de Uberaba (Triângulo Mineiro - MG), devido às descobertas fossilíferas e de depósitos de calcário, economicamente explorados. A partir de dados recentes de superfície e subsuperfície, foi desenvolvida uma análise estratigráfica integrada para as unidades do Grupo Bauru na região do Triângulo Mineiro (MG), estendendo-se sua correlação às áreas adjacentes no nordeste de Mato Grosso do Sul, sul de Goiás e norte São Paulo. Essa análise permitiu refinar o entendimento do arcabouço estratigráfico da Bacia Bauru, bem como identificar através das associações de fácies, 5 ambientes deposicionais geneticamente ligados, constituindo um trato de sistemas aluvial/lacustre. A sedimentação ocorreu a partir de fluxos aluviais advindos principalmente de norte/nordeste (Soerguimento do Alto Paranaíba e Província Alcalina de Goiás), em direção a um nível de base lacustre, hoje balizado pelas cidades de Gurinhatã, Limeira D’Oeste e Prata em Minas Gerais, e que se estendia à porção norte e noroeste do estado de São Paulo. Cessada a sedimentação cretácea, a região norte e nordeste da Bacia Bauru passou por um intenso processo de reestruturação tectônica que resultou na formação de várias depressões onde se encontram preservadas as rochas do Grupo Bauru. Baseado nos dados aqui apresentados foi possível elaborar um modelo paleogeográfico da Bacia Bauru e sua relação com a paleogeografia da América do Sul no Cretáceo Superior.
\end{abstract}

Palavras Chaves: Bacia Bauru, análise estratigráfica, associações de fácies, ambientes deposicionais, trato de sistema aluvial/lacustre, nível de base lacustre, paleogeografia do Cretáceo Superior, reestruturação tectônica terciária.

\begin{abstract}
STRATIGRAPHICS ANALISYS APPLIED TO THE PALEOGEOGRAPHY RECONSTRUCTION OF THE NORTH AND NORTHEAST REGIONS OF THE BAURU BASIN (LATE CRETACEOUS) The Bauru Basin, an Upper Cretaceous sedimentary basin in the southeastern South American Plate, has been studied since the end of $19^{\text {th }}$ Century. In the north and northeast region the investigations were concentrated mainly near the city of Uberaba, due to the large fossil and limestone deposits economically explored there. Based on recent surface and subsurface data, an integrated stratigraphic analysis of the Bauru Group was developed in the Triângulo Mineiro region and extending to the neighboring areas in the northeast of Mato Grosso do Sul, south of Goiás, and north of São Paulo states. This analysis allowed the construction of a paleogeographic evolution model, based on five depositional environments that composed an alluvial/lacustrine systems tract. The alluvial sedimentation entered the basin towards the lacustrine base level (Gurinhatã, Limeira D’Oeste, Prata and western São Paulo region) from the northern/northeastern catchment area (Alto Paranaíba Uplift and Goiás Alkaline Province). After Cretaceous sedimentation ended, the Triângulo Mineiro region was modified by Tertiary tectonic events, which resulted in the formation of various depressions, where remnants of the Bauru Group are preserved. Based on these data it was possible to make the paleogeographic model to the Bauru Basin and to establish the relationship with the Late Cretaceous South America paleogeography.
\end{abstract}

Keywords: Bauru Basin, stratigraphic analysis, facies assemblage, depositional environments, alluvial/lacustrine system tracts, lacustrine base level, Late Cretaceous paleogeography, tertiary tectonic events.

INTRODUÇ̃̃o A Bacia Bauru, entidade geotectônica gerada durante o Cretáceo Superior na porção sudeste da Placa Sul-Americana, sobreposta em parte à antiga Bacia do Paraná, tem sido alvo de inúmeras pesquisas acadêmicas, bem como da potencialidade econômica de suas unidades litoestratigráficas, desde o final do Século XIX (Figura 1).

No contexto dessa bacia, a região do Triângulo Mineiro (MG) e áreas adjacentes nos estados de São Paulo, Mato Grosso do Sul e Goiás corresponde a uma porção cuja sedimentação foi controlada pelos soerguimentos da borda nordeste e norte, relacionados às intrusões alcalinas mesozóicas (SAP - Soerguimento do Alto Paranaíba - Hasui et al., 1975; e PAGO - Província Alcalina de Goiás - Junqueira-Brod et al., 2002) (Figura 1). Além disso, a região em apreço corresponde a uma zona intensamente reestruturada pelas movimentações cenozóicas, onde as unidades litoestratigráficas cretáceas encontram-se preserva- das em depressões com diferentes espessuras.

Apesar de abrigar um dos registros geológicos cretáceos mais bem documentado do Brasil, a Bacia Bauru é objeto de, comparativamente, poucos trabalhos envolvendo conceitos estratigráficos modernos, sendo que a maioria deles se restringem às informações restritas a pequenas áreas. Com exceção de poucos trabalhos de caráter regional (como por exemplo: Hasui, 1967; Barbosa et al., 1970; Barcelos, 1984; e mais recentemente Batezelli, 2003), a grande maioria dos trabalhos realizados até o momento, refere-se ao conteúdo paleontológico da área, análises petrográficas e diagenéticas, e pesquisas localizadas para calcário e diamante (Alves, 1995; Goldberg, 1995; Ferreira Jr.; 1996, Ribeiro, 1997; Dias-Brito et al., 2001; Santucci \& Bertini, 2001).

A partir de informações integradas de superfície e subsuperfície, foi desenvolvida uma análise estratigráfica para a Bacia Bauru na região do Triângulo Mineiro, estendendo-se sua corre-

1 - Rua 5, 646 - Centro Cep 13500-040 - Rio Claro - SP - alessandro.batezelli@gmail.com

2 - Praça Tereza Cristina, 1 - Centro - Cep - 07023-070 - Guarulhos - SP. - asaad@prof.ung.br

3 - Departamento de Geologia Aplicada, Instituto de Geociências e Ciências Exatas, Universidade Estadual Paulista - IGCE/UNESP - Av. 24-A, 1515 - Bela Vista

- Cep 13506-900 - Rio Claro - SP. - perinoto@rc.unesp.br

4 - Departamento de Geologia Aplicada, Instituto de Geociências e Ciências Exatas, Universidade Estadual Paulista - IGCE/UNESP - Av. 24-A, 1515 - Bela Vista

- Cep 13506-900 - Rio Claro - SP. - fulfaro@rc.unesp.br 


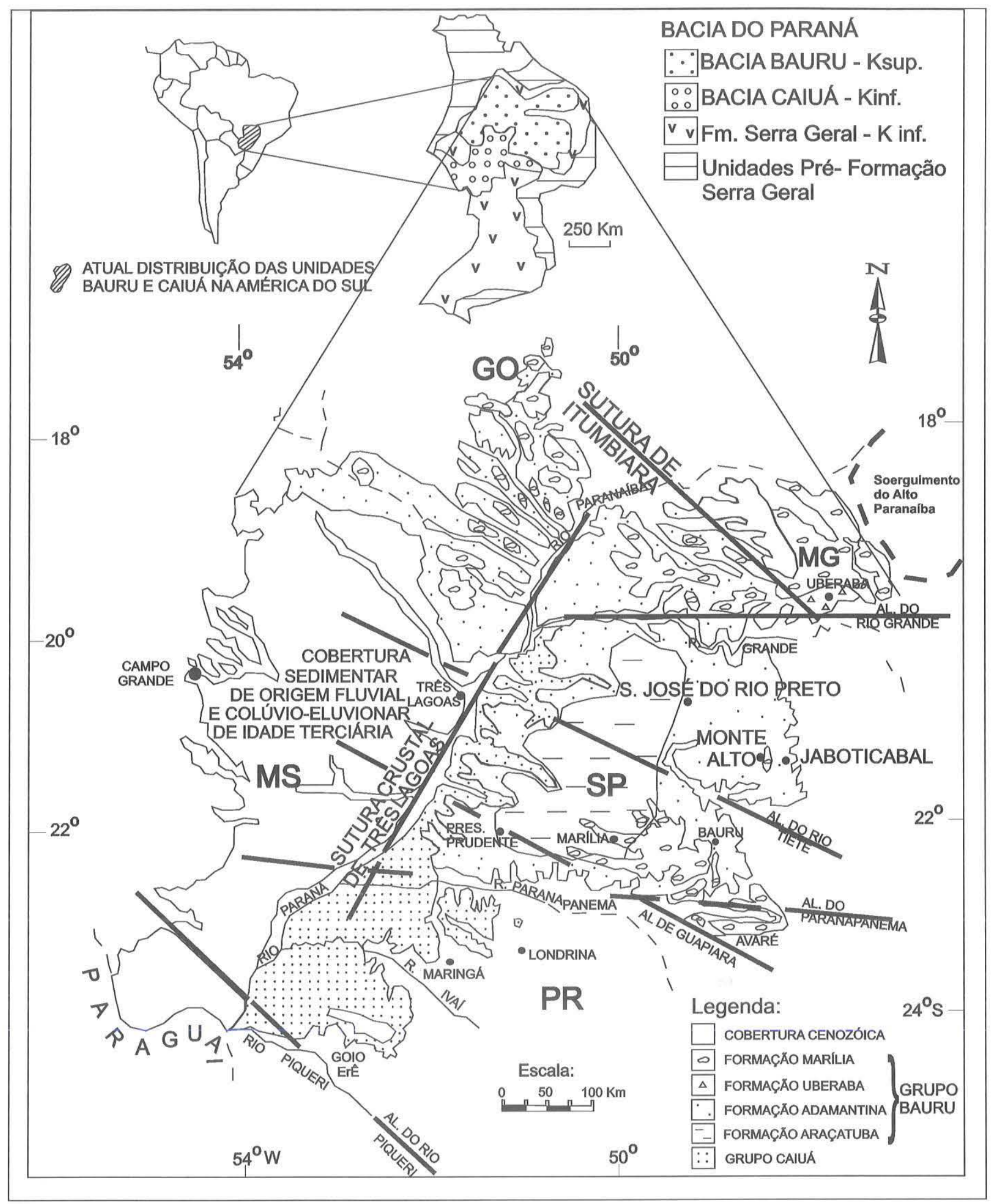

Figura 1 - Localização da Bacia Bauru e distribuição das unidades litoestratigráficas (Batezelli, 2003).

lação às áreas adjacentes (Figura 2). Essa análise permitiu elaborar um modelo de evolução paleogeográfica, estabelecendo a ligação genética de seus ambientes deposicionais em um trato de sistemas aluvial/lacustre, e sua relação com a paleogeografia da América do Sul no Cretáceo Superior.

\section{A BACIA BAURU}

Generalidades A Bacia Bauru corresponde a uma entidade geotectônica gerada no Cretáceo Superior por processos de abatimento relacionados à reativação de lineamentos do em- 


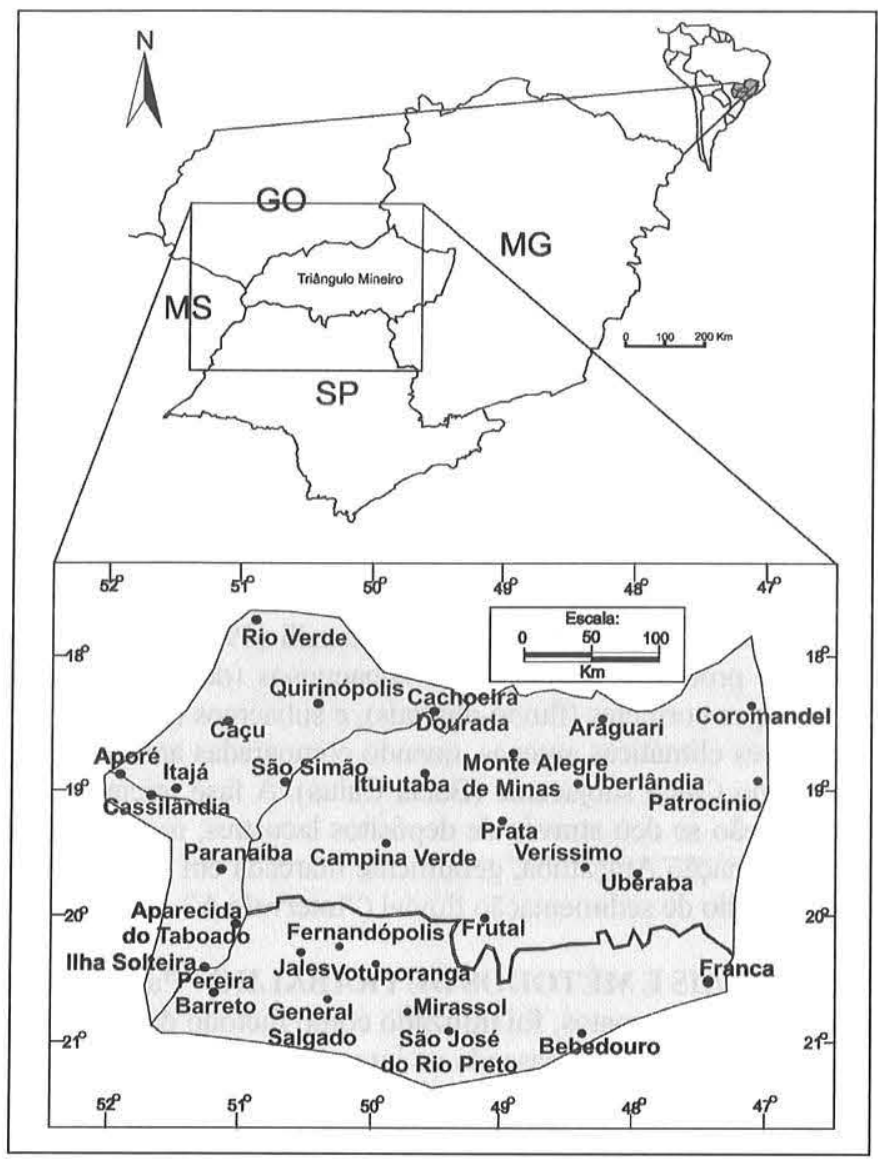

Figura 2 - Mapa de localização da área de estudo. basamento pré-cambriano (Três Lagoas, Presidente Prudente e Ribeirão Preto - Hasui et al., 1989), tendo sido implantada na porção centro-norte da antiga Bacia do Paraná, tanto sobre os arenitos do Grupo Caiuá (Aptiano-Albiano - Fulfaro et al., 1999; Dias-Brito et al., 2001), como sobre os basaltos da Formação Serra Geral (132 M.a. - Valangiano - Renne, 1997). Abrange uma área com aproximadamente $330.000 \mathrm{~km}^{2}$, ocupando o oeste do Estado de São Paulo, leste do Mato Grosso do Sul, sul de Goiás e Triângulo Mineiro (Figura 1). O limite entre os grupos Bauru e Caiuá é marcado por uma superfície de descontinuidade que separa os arenitos da Formação Santo Anastácio (base), dos siltitos esverdeados da Formação Araçatuba, e que pode ser rasteada, em superfície, desde Vitória Brasil (SP), a norte, até Marabá Paulista (SP), a sul (Figura 3) (Batezelli et al., 2003). Sobre essa superfície repousa um depósito arenoso fino, com espessura máxima de 2 metros, estratificações cruzadas acanaladas de pequeno a médio porte (até 1,5 metros de fore$s e t)$ e estratificações plano-paralelas, que pode ser reconhecido em boa parte da bacia, caracterizando o início de um evento de sedimentação subaquosa, diferente do anterior ("Ciclo Caiuá"), predominantemente desértico.

Com formato alongado na direção aproximada norte, essa bacia abriga rochas argilo-arenosas na base, gradando essencialmente para arenosas e conglomeráticas no topo, com espessura máxima preservada de quase 250 metros (região de Marília no Estado de São Paulo - Batezelli et al. 2003). Os limites atuais da Bacia Bauru são essencialmente erosivos e/ou tectônicos, desenhados pela Antéclise de Rondonópolis (Coimbra, 1991), a noroeste, Soerguimento do Alto Paranaíba (Hasui \& Haralyi, 1991), a nordeste, alinhamentos do Rio Moji Guaçú (Coimbra et al., 1981), São Carlos-Leme e Ibitinga-Botucatu (Riccomini, 1995), a leste, do Paranapanema (Fulfaro, 1974), a sul e sudeste. A oeste

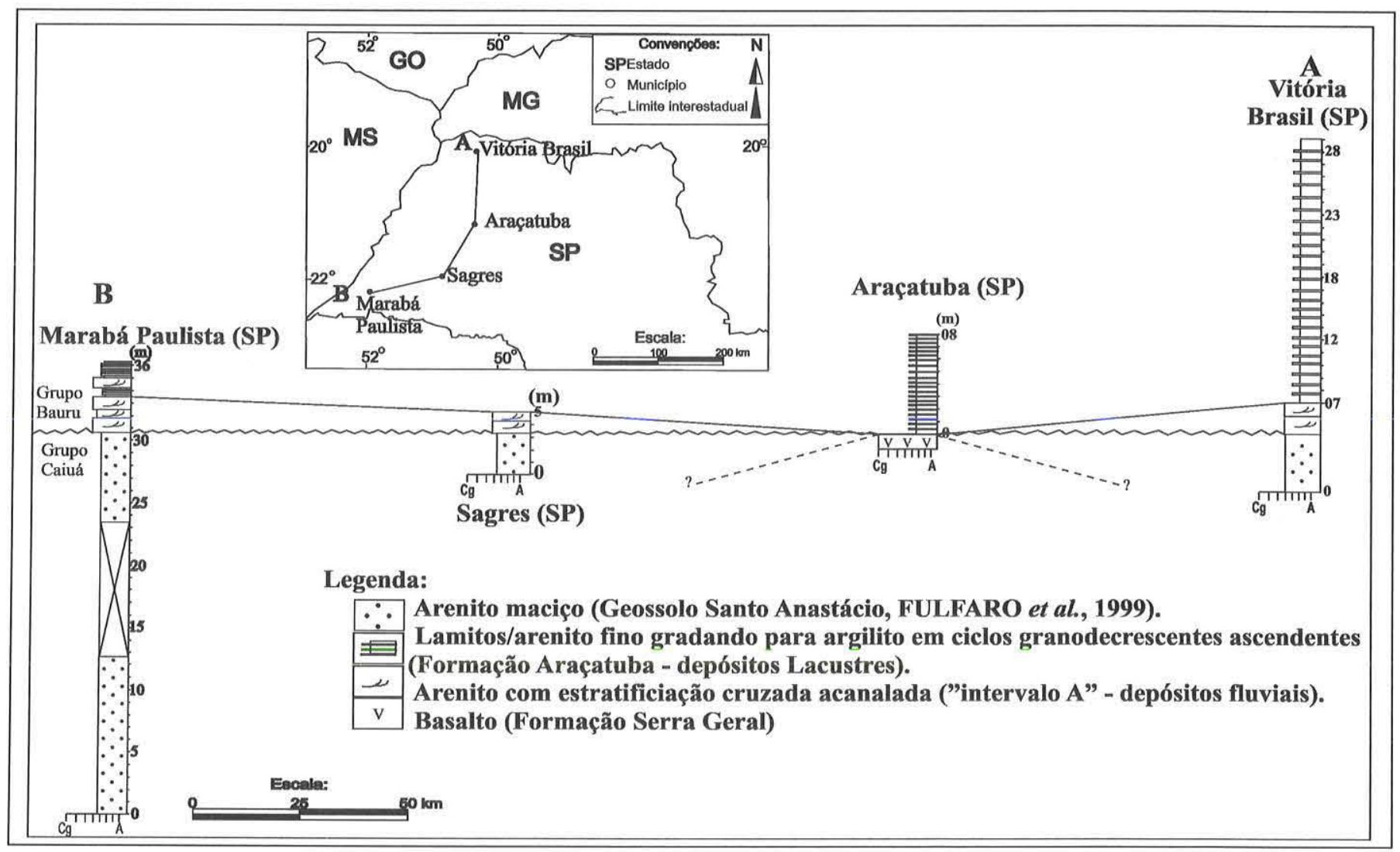

Figura 3 - Seção estratigráfica Vitória Brasil (SP) - Marabá Paulista (SP), mostrando relações de contato entre as formações Santo Anastácio (Grupo Caiuá) e Araçatuba (Grupo Bauru, em superficie (Batezelli et al, 2003a). 


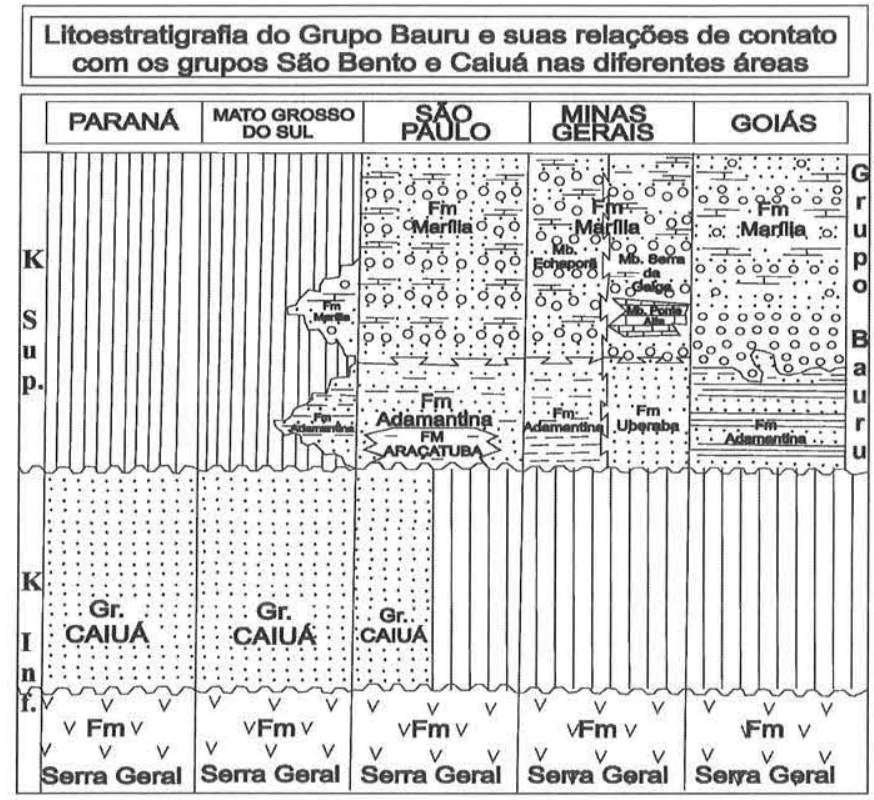

Figura 4 - Coluna litoestratigráfica do Grupo Bauru nas diferentes áreas de ocorrência (BATEZELLI, 2003).

seu limite é difuso dada à grande área dominada por depósitos de cobertura sedimentar aluvial de idade terciária. Os processos erosivos responsáveis pela atual configuração dos limites da Bacia Bauru estão relacionados ao evento de reestruturação tectônica terciária, marcado em sua borda oriental pelo levantamento da Serra do Mar e Soerguimento do Alto Paranaíba.

Estratigrafia da Bacia Bauru $\mathrm{O}$ arranjo tridimensional das rochas sedimentares que preenchem a Bacia Bauru constitui matéria amplamente discutida na bibliografia geocientífica, desde o início do século 20. O termo Bauru foi introduzido na literatura geológica por Gonzaga de Campos (1905), após ter sido reconhecido e descrito na região oeste do Estado de São Paulo. A princípio se propôs a denominação de "Grês de Bauru", modificada mais tarde para "Arenito Bauru". Em 1930, a Comissão Geográfica e Geológica do Estado de São Paulo, atual Instituto Geológico, adotou o nome de "Formação Bauru" (Washburne, 1930). A partir de 1974, os levantamentos geológicos no Estado de São Paulo em área de ocorrência do Grupo Bauru começaram a se intensificar devido aos diversos convênios do Departamento de Águas e Energia Elétrica do Estado de São Paulo (DAEE) com a Universidade Estadual Paulista - UNESP, Universidade de São Paulo - USP e o Instituto de Pesquisas Tecnológicas do Estado de São Paulo - IPT. Esses estudos contribuíram consideravelmente para uma melhor visão estratigráfica desse grupo, já subdividido em unidades menores, mapeáveis na escala 1:25.000, ainda com a denominação informal de litofácies e mesmo de fácies. Após os trabalhos de Soares \& Landim (1975) e Suguio et al. (1977), a "Formação" Bauru poderia ter sido elevada à categoria de grupo, quando foi reconhecida a mapeabilidade de suas litofacies segundo os critérios do Código de Nomenclatura Estratigráfica Internacional. Segundo Barcelos (1984), isso não ocorreu devido ao fato de que nessa época, os autores preferiam ponderar mais sobre tais divisões, optando por manter a individualização em fácies. Só a partir dos trabalhos de Soares et al. (1980) e Suguio (1980) é que foi proposta uma das mais aceitas subdivisões estratigráficas do Grupo Bauru, em função de sua operacionalidade. Segundo essa concepção, o Grupo Bauru era entendido como constituído pelas formações Caiuá, Santo Anastácio, Adamantina, Uberaba e Marília (Soares et al., 1980).

A partir da década de 90, essa unidade sofreu modificações do ponto de vista estratigráfico, em função das várias pesquisas abrangendo os estados de São Paulo, Paraná, Minas Gerais e Goiás (por exemplo: Fernandes, 1992 e 1998; Fulfaro et al., 1994; Fernandes \& Coimbra, 1996; Fulfaro \& Perinotto, 1996; Batezelli, 1998 e 2003; Fernandes \& Coimbra, 2000).

O presente trabalho segue as concepções estratigráficas propostas por Batezelli (2003), Batezelli et al. (2003) e Batezelli et al. (2005), admitindo o Grupo Bauru como o registro de sedimentação continental, constituído por rochas lamíticas na base (formações Araçatuba e Adamantina), gradando para arenitos e conglomerados no topo (formações Adamantina, Uberaba e Marília - Figura 4), depositadas em 5 ambientes geneticamente ligados, constituindo um trato de sistema lacustre/aluvial, conforme já aventado por outros autores, como por exemplo Etchebehere et al. (1993); Fernandes (1998) e Batezelli (1998). Suas fácies indicam processos sedimentares subaquosos (decantação), tracionais por correntes (fluvio-aluviais), e subaéreos (eólicos), sob condições climáticas amenas, quando comparadas aos depósitos do Grupo Caiuá subjacente (Bacia Caiuá). A fase inicial de sedimentação se deu através de depósitos lacustres, representados pela Formação Araçatuba, geralmente marcada em sua base por um episódio de sedimentação fluvial ("Intervalo A" - Figura 3).

MATERIAIS E MÉTODOS DE TRABALHO Para alcançar os objetivos propostos, foi utilizado como método de trabalho a Análise estratigráfica baseada na integração de dados de superfície e subsuperfície, usando como ferramentas estratigráficas à análise de fácies, correlação e mapeamento estratigráfico.

Os trabalhos de superfície consistiram da descrição e documentação fotográfica de afloramentos, levantamento de seções colunares, geológicas e estratigráficas, coleta de amostras para análises petrográfica, paleontológica (palinologia e micropaleontologia) e paleomagnética, que forneceram informações adicionais às interpretações.

Quanto aos trabalhos envolvendo dados de subsuperfície, foram construídas seções colunares litológicas de poços tubulares profundos, a partir de informações obtidas junto aos departamentos de água e esgoto dos estados de Minas Gerais (COPASA), São Paulo (DAAE), e empresas de perfuração de poços, que serviram de base para a análise de fácies, além da confecção de seções e mapas estratigráficos, permitindo assim tecer importantes considerações sobre o comportamento das unidades em profundidade.

A análise estrutural envolvendo informações obtidas em campo e a partir de análises fotointerpretativas de imagens de satélite (LANDSAT, do Instituto de Pesquisas Espaciais - INPE, em cópias dos canais 5 e 7, variações de cinza, em escala 1:500.000), possibilitou a elaboração do mapa com as duas principais depressões onde estão preservadas as rochas do Grupo Bauru no Triângulo Mineiro (MG), subsidiando às interpretações sobre uma reestruturação tectônica da porção NE e N da Bacia Bauru, após o evento deposicional de idade provável terciária.

O tratamento e integração dos dados forneceram como principais produtos: mapa de isólitas e de contorno estrutural do topo da Formação Serra Geral, mapa de isópacas do Grupo Bauru, mapa de fácies sedimentares do Grupo Bauru e mapa paleogeográfico, bem como seções estratigráficas e estruturais (superfície e subsuperfície).

A partir das informações levantadas, é proposto um modelo de evolução paleogeográfica para a Bacia Bauru, desde sua formação no Cretáceo Superior até sua reestruturação durante o Cenozóico, estabelecendo sua relação com a posição paleogeográfica da Placa Sul-americana. 
FÁCIES, ASSOCIAÇÕES E ARCABOUÇO ESTRATIGRÁFICO. A partir dos trabalhos de campo na área do Triângulo Mineiro (MG) e em regiões adjacentes (sul de Goiás, nordeste do Mato Grosso do Sul e norte/noroeste de São Paulo), buscou-se mediante descrições sistemáticas de afloramentos e de dados de subsuperfície, identificar as principais fácies que compõem o conjunto de rochas do Grupo Bauru para essa região.

Foi atribuída a cada uma das fácies identificadas, um código baseado na proposta de Miall (1985), no qual a litologia é indicada por uma letra maiúscula $(\mathrm{C}=$ conglomerado, $\mathrm{A}=$ Arenito, $\mathrm{F}=$ Finos, $\mathrm{L}=$ Calcário), seguida por uma letra minúscula indicativa de uma característica marcante da fácies. Quando necessário, adicionou-se uma terceira ou quarta letra para indicar atributos que a diferenciassem das demais fácies (Quadro 1).

A partir da análise de fácies e do empilhamento observado em campo e nos perfis de poços tubulares profundos, foi possível identificar 5 associações de fácies que indicam, através de seus atributos, 5 ambientes deposicionais geneticamente relacionados e que estão sendo apresentadas com a denominação: Associação 1 (ou Associação de fácies lacustre); Associação 2 (ou Associação de fácies fluvial meandrante); Associação 3 (ou Associação de fácies fluvial entrelaçado); Associação 4 (ou Associação de fácies de leque intermediário); e Associação 5 (ou Associação de fácies de leque proximal) (Figuras 5 e 6). O quadro 2 mostra a relação entre as fácies, associações de fácies, ambientes deposicionais, unidades litoestratigráficas e áreas de ocorrência.

A identificação dessas associações, tanto nas seções colunares de afloramento como de subsuperfície, permitiu sua correlação através de 2 seções estratigráficas (Figuras 7, 8).

Na seção estratigráfica de superfície, Itajá (MS) - Pedregulho (SP) (Figura 7), observa-se que a Associação 1 possui uma grande distribuição em área, podendo ser rastreada em toda a seção. Está sobreposta pela Associação 2, que por sua vez encontra-se colmatada pela a Associação 4. As maiores espessuras da Associação 1 estão preservadas no trecho balizado pelas cidades Prata (MG), Gurinhatã (MG), Limeira D’Oeste (MG) e União de Minas (MG). A ausência de dados faciológicos precisos impossibilita o reconhecimento individualizado das associações 2 e 3 , e, 4 e 5 , o mesmo comportamento observado nas seções de afloramento é identificado nas seções de subsuperfície (Figura 8).
A seção Ponte Alta (MG) - Carneirinho (MG) (Figura 8) que tem como referência a base das associações 4 e 5 , apresenta duas depressões, uma a leste e outra a oeste, separadas por um alto estrutural entre Campo Florido e Comendador Gomes. No extremo leste, nas proximidades da cidade de Uberaba (Depressão de Uberaba), encontram-se preservadas as associações 3,4 e 5 , litoestratigraficamente correspondentes às formações Uberaba e Marília. Na porção oeste, entre Comendador Gomes e Carneirinho, encontram-se preservadas as associações 1 e 2 (Formação Adamantina/Araçatuba).

A presença de em estrato arenoso com 100 metros de espessura no poço ITUR-03 sugere a presença de rochas do Grupo Caiuá, preservadas em grabens.

Conforme Batezelli (2003), a porção oeste do Triângulo Mineiro $(M G)$ é caracterizada por uma área deprimida denominada de Depressão de Gurinhatã, onde se encontram as maiores espessuras preservadas da Associação 1 .

RECONSTRUÇÃO PALEOGEOGRÁFICA DA PORÇÃO NORTE E NORDESTE DA BACIA BAURU A elaboração do modelo paleogeográfico para a época de sedimentação do Grupo Bauru é baseada nos mapas de isópacas (Figura 9) e de isoporcentagem de sedimentos finos (Figura 10) do Grupo Bauru, além dos mapas de isólitas do basalto e contorno estrutural do topo da Formação Serra Geral (Figuras 11 e 12) que constitui o embasamento da Bacia Bauru na área estudada. Esses mapas foram confeccionados a partir de informações extraídas de perfis litológicos de poços tubulares profundos.

A existência de várias áreas deprimidas nessa porção da Bacia Bauru fica clara através da análise do mapa de isópacas do Grupo Bauru (Figura 9), onde essa unidade apresenta valores de espessuras maiores em relação à média regional $(30$ a 40 metros): Uberaba (60 - 70 metros), Ponte Alta (100 metros), Comendador Gomes (100 metros), União de Minas (190 metros), Limeira do Oeste (90 metros), Gurinhatã (80 metros), Fernandópolis (180 metros) e General Salgado (180 metros). De maneira geral, as maiores espessuras preservadas do Grupo Bauru estão situadas no eixo Gurinhatã (MG) - General Salgado (SP) de direção norte-sul, coincidindo com a área de maior espessura de basaltos da Formação Serra Geral (Figura 11) e com a diminuição nos valores das cotas topográficas do topo dessa mesma unidade. (Figura 12).

Quadro 1 - Código de fácies utilizado no estudo do Grupo Bauru no Triângulo Mineiro e áreas adjacentes.

\begin{tabular}{|c|c|c|}
\hline $\begin{array}{l}\text { Conjunto de } \\
\text { Fácies }\end{array}$ & Fácies & Características \\
\hline \multirow{5}{*}{$\mathrm{C}$} & Cmm & Conglomerado maciço, sustentado por matriz arenosa média a grossa. \\
\hline & Cmg & Conglomerado maciço, sustentado por clastos. \\
\hline & Ceag & Conglomerado com estratificação cruzada acanalada, sustentado por clastos. \\
\hline & Ceam & Conglomerado com estratificação cruzada acanalada, sustentado por matriz arenosa média a grossa. \\
\hline & Cetg & Conglomerado com estratificação cruzada tabular, sustentado por clastos. \\
\hline \multirow{8}{*}{ A } & Am & Arenito maciço, com ou sem clastos dispersos. \\
\hline & Aea & Arenito com estratificação cruzada acanalada (pequeno Aeap, médio Aeam e grande porte Aeag). \\
\hline & Aeab & Arenito com estratificação cruzada acanalada de baixo ângulo. \\
\hline & Aet & Arenito com estratificação cruzada tabular (pequeno, médio e grande porte). \\
\hline & Aeh & Arenito com estratificação sub-horizontal. \\
\hline & Alp & Arenito com laminação plano-paralela. \\
\hline & Ao & Arenito com marcas onduladas. \\
\hline & Ar & Arenito granodecrescente ascendente. \\
\hline \multirow{3}{*}{$\mathbf{F}$} & Fm & Argilito maciço. \\
\hline & Fma & Lamito maciço com lentes de arenito. \\
\hline & Fs & Siltito \\
\hline $\mathbf{L}$ & Lm & Calcário maciço. \\
\hline
\end{tabular}


Na região balizada pelas cidades de Ponte Alta (MG), Conceição das Alagoas (MG) e Patrimônio do Rio do Peixe (MG), a espessura máxima preservada do Grupo Bauru é da ordem de 100 metros. Esses depósitos estão alinhados segundo uma feição estrutural de direção SE-NW, denominada Sutura de Itumbiara (Hasui et al., 1989).

No sudoeste de Goiás e nordeste do Mato Grosso do Sul, a espessura média do Grupo Bauru é da ordem de 60 metros. No noroeste do estado de São Paulo está preservada uma grande espessura dessa unidade. $\mathrm{Na}$ área balizada pelas cidades de Votuporanga, Fernandópolis, General Salgado e Jales, a proximidade das isolinhas indica uma grande área deprimida onde o acúmulo de sedimentos ultrapassou 180 metros.

O mapa de contorno estrutural do topo da Formação Serra Geral (Figura 12) apresenta uma diminuição dos valores da cota topográfica (em relação ao nível do mar) no rumo ENE-WSW. Constata-se nesse mapa uma área mais subsidente na parte oeste do Triângulo Mineiro (MG) e noroeste do estado de São Paulo, compreendida pelos municípios de Limeira do Oeste, União de Minas, Gurinhatã, Votuporanga, General Salgado e Jales, na qual o menor valor verificado foi da isolinha de 325 metros de altitude, em relação ao nível do mar. No extremo leste do Triângulo Mineiro, os valores obtidos para o topo dos basaltos foram de até 900 metros de altitude (Figura 12).

Embora os registros indiquem que essa estruturação seja posterior à deposição do Grupo Bauru, os dados faciológicos e de paleocorrentes indicam que a região compreendida pelos municípios de Limeira do Oeste, União de Minas, Gurinhatã, Votuporanga, General Salgado e Jales, funcionava como nível de base local para a Bacia Bauru.

Medidas de rumos de paleocorrentes (Batezelli, 2003), indicam que existia uma tendência marcante no padrão de drenagem no rumo W e SW, coincidindo com a diminuição nos valores da cota topográfica do topo da Formação Serra Geral e com o aumento da espessura do Grupo Bauru. Essa constatação sugere que o depocentro da Bacia Bauru, provavelmente, possuiu um eixo de direção NNW-SSE, se estendendo da região de Gurinhatã (MG) em direção a Jales e General Salgado em São Paulo. A principal área-fonte dessa porção da Bacia Bauru se localizava a leste/nordeste, na região do Soerguimento do Alto Paranaíba.

Seguramente, a bacia teve contribuição de sedimentos oriundos da erosão de áreas soerguidas localizadas a norte, na faixa conhecida como Arco de Bom Jardim de Goiás (Almeida, 1983; Almeida, 1986, Fulfaro et al., 1994), Província Alcalina Iporá - Rio Verde (Almeida, 1983; Fernandes \& Coimbra, 1996), ou Província Alcalina de Goiás (Danni, 1996; Junqueira-Brod et al., 2002), cuja gênese está relacionada ao mesmo evento que deu origem ao Soerguimento do Alto Paranaíba (passagem de pluma astenosférica, segundo Gibson et al., 1995).

Ainda na direção aproximada norte-sul, na área balizada pelas cidades de Miraporanga (MG), Ituiutaba (MG), Limeira D'Oeste (MG), Iturama (MG) e Fernandópolis (SP) encontravase o nível de base para a sedimentação do Grupo Bauru. Essa hipótese fica bastante evidente na análise do mapa de isoporcentagem de sedimentos finos (Figura 10), endossando o que foi apresentado nas seções estratigráficas. Observa-se no mapa que as fácies finas (Associações 1 e 2) possuem uma tendência maior de se concentrar nessa região.

Por outro lado, as fácies mais grossas (Associações 3, 4 e 5 ) tendem a predominar nas porções leste e centro-norte do Triângulo Mineiro, sul e sudoeste de Goiás, e nordeste do Mato Grosso do Sul (Figura 10).

Com base nesses dados, a provável distribuição dos ambientes que deram origem às rochas do Grupo Bauru seria representada pelo mapa paleogeográfico da figura 13. Essa interpretação está de acordo com Etchebehere et al. (1993), Batezelli (1998 e 2003), Batezelli et al. (2003) e Batezelli et al. (2005).

EVOLUÇÃO TECTONOSSEDIMENTAR DA BORDA NORTE E NORDESTE DA BACIA BAURU Após o ciclo de sedimentação desértico que deu origem às rochas do Grupo Caiuá (Bacia Caiuá - Aptiano/Albiano, segundo Dias-Brito et

Quadro 2 - Síntese das principais características das associações de fácies do Grupo Bauru no Triângulo Mineiro (MG) e áreas adjacentes.

\begin{tabular}{|c|c|c|c|c|c|c|}
\hline $\begin{array}{l}\text { Associação de } \\
\text { Fácies }\end{array}$ & Fácies & $\begin{array}{l}\text { Sistema } \\
\text { Deposicional }\end{array}$ & Subsistemas & $\begin{array}{l}\text { Ambientes } \\
\text { Deposicionais }\end{array}$ & $\begin{array}{l}\text { Litoestra- } \\
\text { tigrafia }\end{array}$ & $\begin{array}{ll}\begin{array}{l}\text { Á re a s } \\
\text { ocorrência }\end{array} & \text { d e } \\
\end{array}$ \\
\hline Associação 5 & $\begin{array}{l}\text { Cmg, Cmm, } \\
\text { Ceag, Cetg, } \\
\text { Lm, Am. }\end{array}$ & \multirow{4}{*}{ Aluvial } & Proximal & \multirow[t]{2}{*}{ Leque Aluvial } & \multirow{2}{*}{$\begin{array}{c}\text { Formação } \\
\text { Marília }\end{array}$} & \multirow{2}{*}{$\begin{array}{l}\text { Quirinópolis } \\
\text { (GO), Canápolis, } \\
\text { Prata, } \\
\text { Ponte Alta, } \\
\text { Uberaba, Frutal } \\
\text { (MG). }\end{array}$} \\
\hline Associação 4 & $\begin{array}{l}\text { Cmm, Ceam, } \\
\text { Am. }\end{array}$ & & $\begin{array}{c}\text { A } \\
\text { Intermediário }\end{array}$ & & & \\
\hline Associação 3 & $\begin{array}{l}\text { Ceam, Am, } \\
\text { Aea, Aet, } \\
\text { Aeh. }\end{array}$ & & Intermediário & $\begin{array}{c}\text { Fluvial } \\
\text { Entrelaçado }\end{array}$ & $\begin{array}{l}\text { Formações } \\
\text { Marilia e } \\
\text { Uberaba }\end{array}$ & $\begin{array}{l}\text { Frutal, } \\
\text { Ituiutataba, } \\
\text { Comendador } \\
\text { G o m e s } \\
\text { Uberaba (MG) }\end{array}$ \\
\hline Associação 2 & $\begin{array}{l}\text { Ceam, Am, } \\
\text { Aea, Alp, } \\
\text { Fm, Fma. }\end{array}$ & & $\begin{array}{l}\text { Intermediário a } \\
\text { Distal }\end{array}$ & $\begin{array}{l}\text { Meandrante } \\
\text { Psamítico }\end{array}$ & \multirow[t]{2}{*}{ Formação } & $\begin{array}{l}\text { Prata, Conceição } \\
\text { das Alagoas, } \\
\text { Limeira D'Oeste } \\
\text { (MG), } \\
\text { Fernandópolis } \\
\text { (SP). }\end{array}$ \\
\hline Associação 1 & $\begin{array}{lr}\text { Aeag, } & \text { Ar, } \\
\text { Ao, } & \text { Fm, } \\
\text { Fma, Fs. } & \end{array}$ & Lacustre & Distal & Lacustre & & $\begin{array}{l}\text { Gurinhatã, } \\
\text { Limeira D'Oeste, } \\
\text { União de Minas } \\
\text { (MG), Jales (SP). }\end{array}$ \\
\hline
\end{tabular}


al., 2001), a região sudeste da Placa Sulamericana tornou-se palco de um ciclo sedimentar caracterizada por processos lacustres e aluviais. Os sucessivos esforços impostos no interior da placa durante a separação Brasil - África, a leste, e colisão com a Placa de

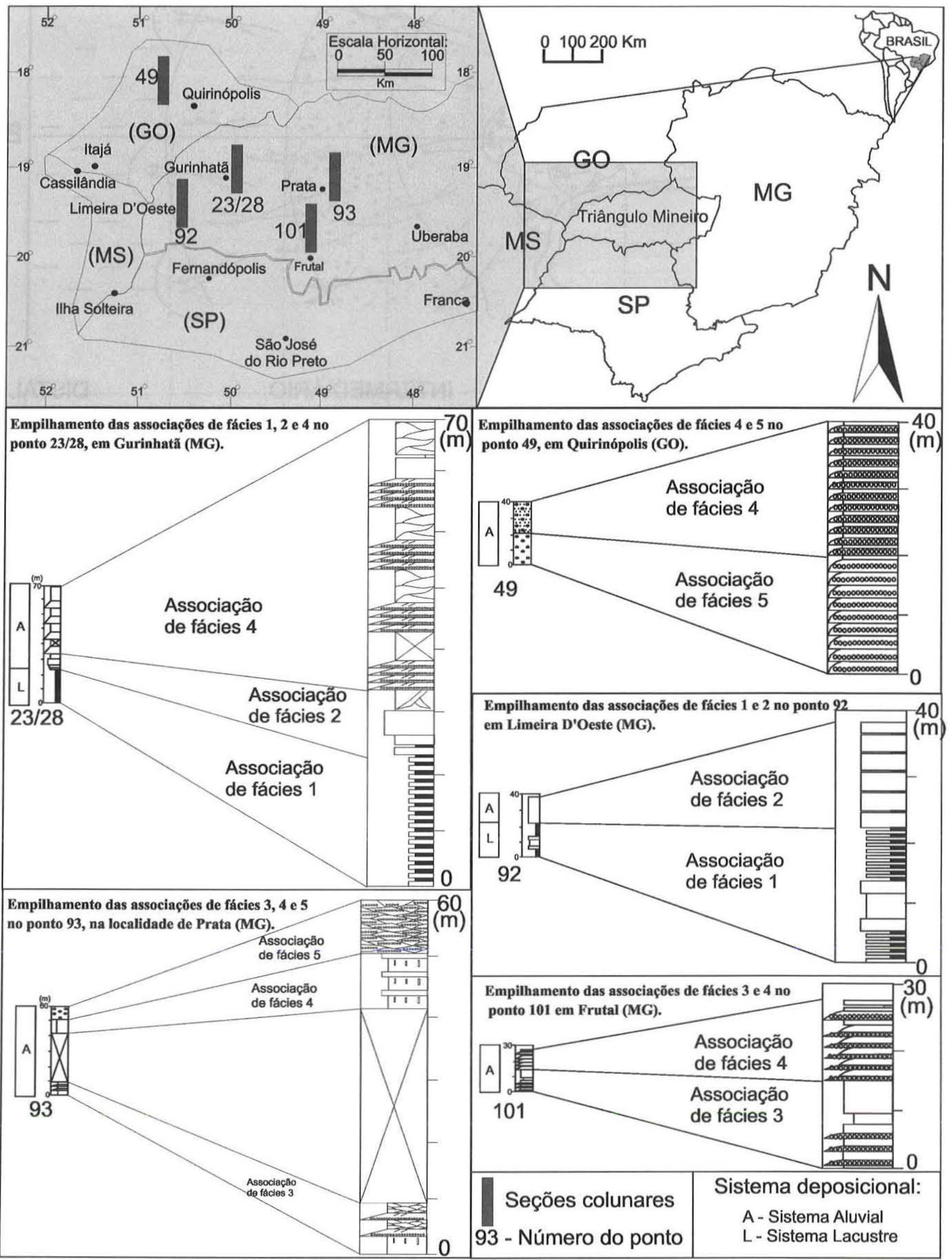

Figura 5 - Empilhamento das associações de fácies 1 a 5 em vários pontos da área de estudo. 


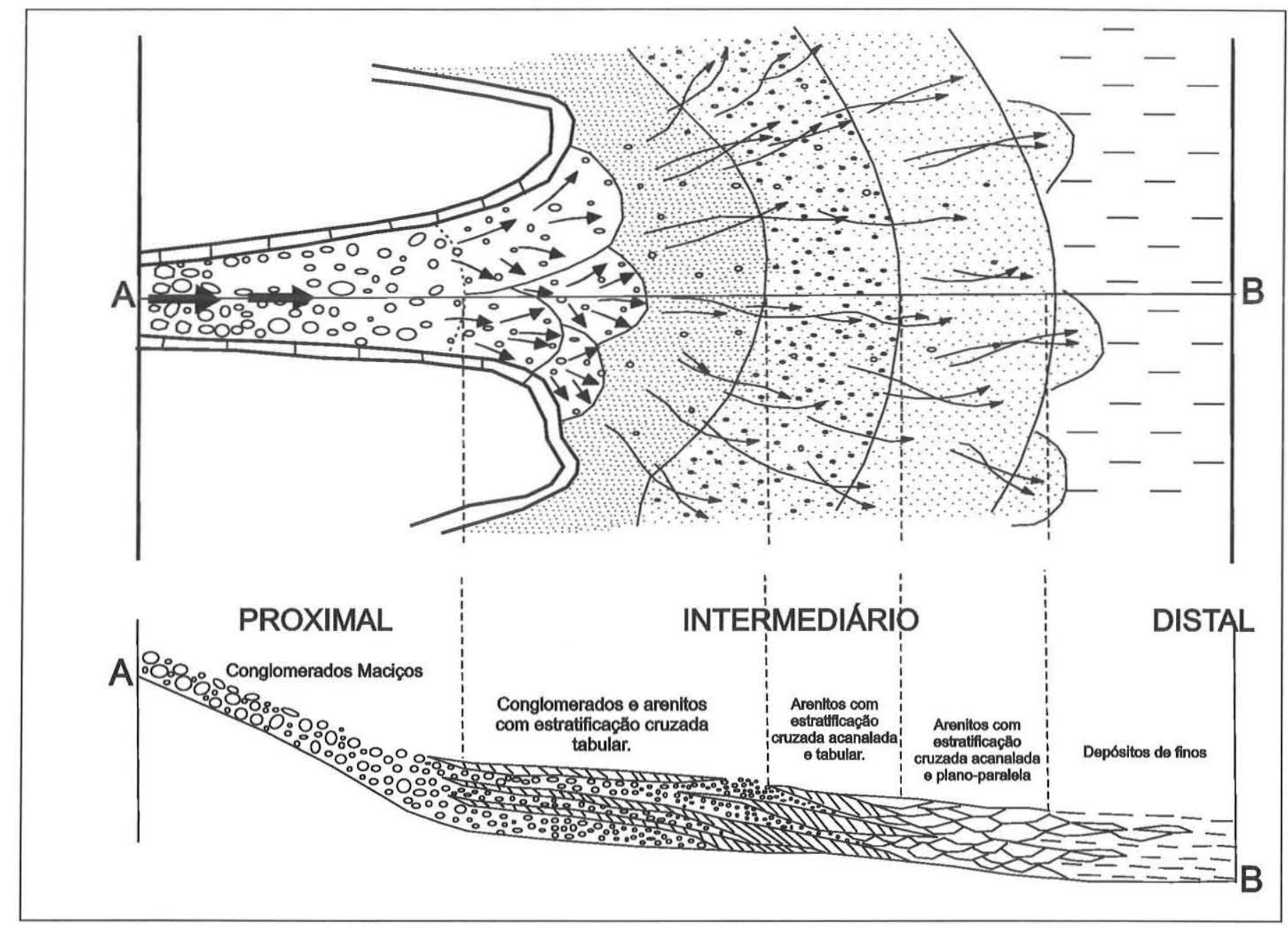

Figura 6 - Visão em planta e perfil longitudinal idealizado de um sistema de leque aluvial. (Galloway \& Hobday, 1983 - Modificado por Batezelli, 2003).

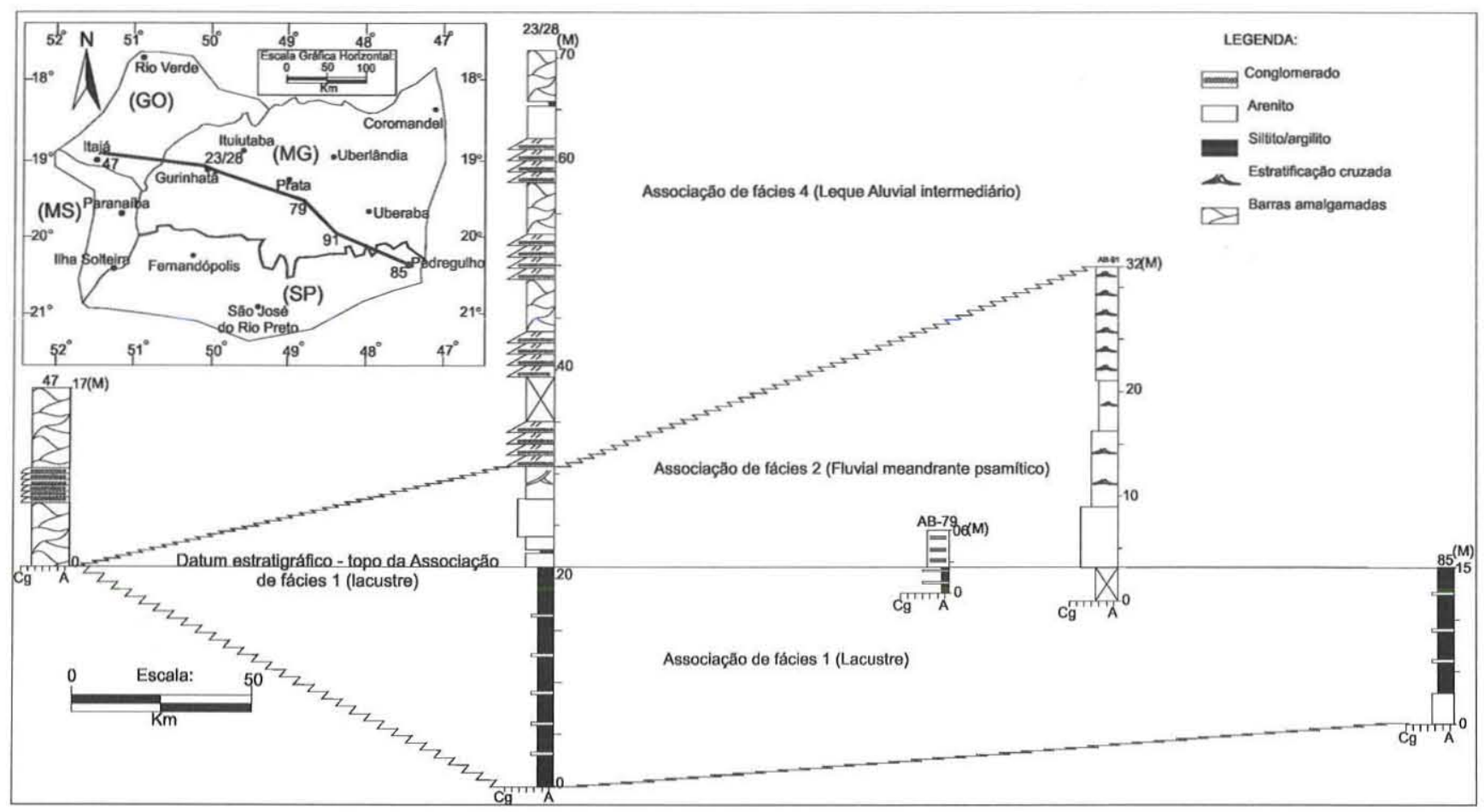

Figura 7 - Seção estratigráfica de subsuperficie Itajá (GO) - Pedregulho (SP). 


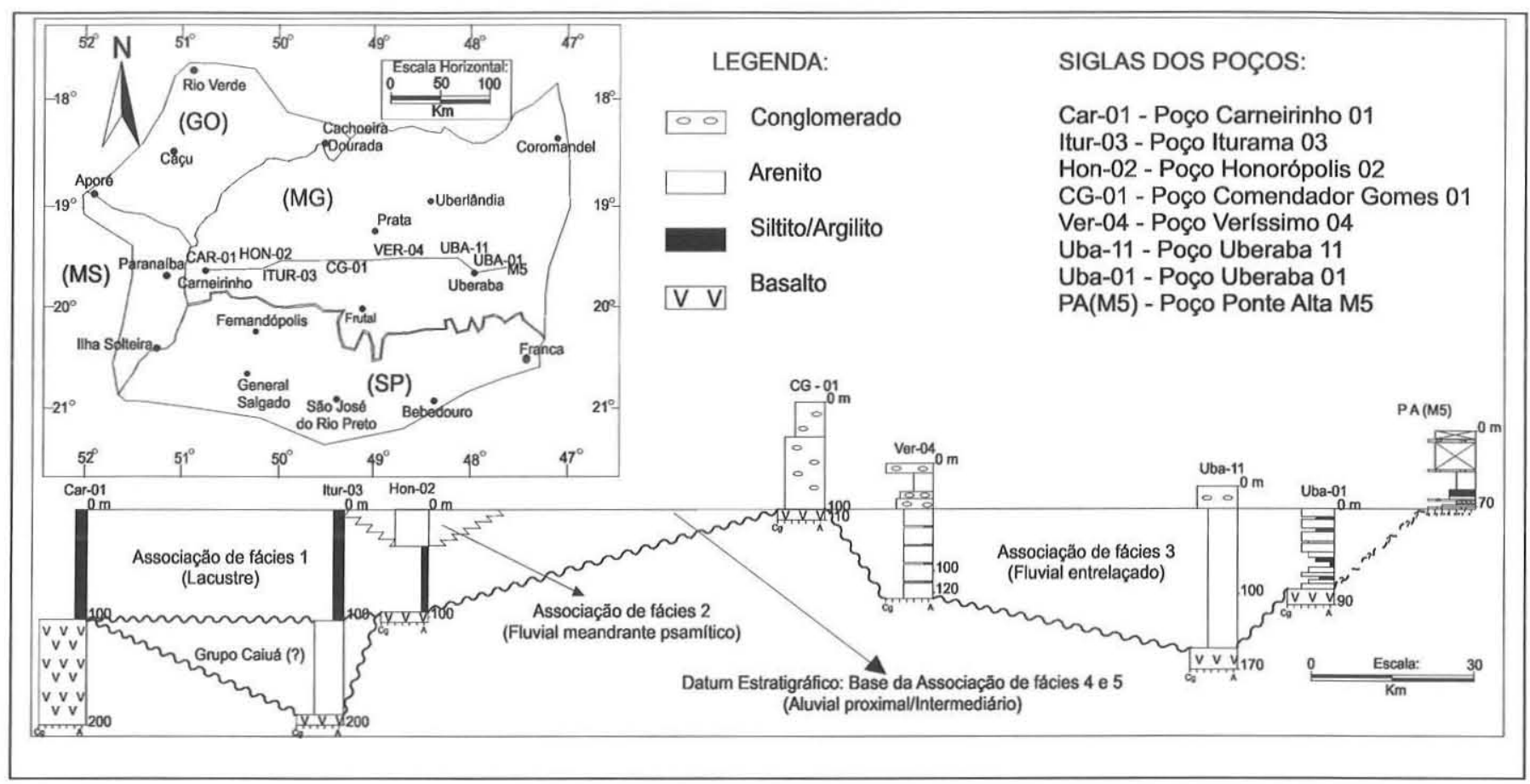

Figura 8 - Seção estratigráfica de subsuperficie Ponte Alta (MG) - Carneirinho (MG).

Nazca, a oeste, fizeram com que muitas estruturas do embasamento pré-cambriano fossem reativadas, causando vulcanismo de caráter alcalino, com movimentos de ascensão e abatimentos de blocos (Figura 14).

A região leste do Triângulo Mineiro (MG) e sul de Goiás foi palco de inúmeras intrusões alcalinas que deram origem aos plugs vulcânicos de Tapira, Araxá, Salitre, Pântano, Serra Negra, Catalão, entre outros (Figura 1).

$\mathrm{O}$ intenso vulcanismo nessa região deu origem a uma grande feição estrutural positiva, denominada Soerguimento do Alto Paranaiba (Hasui et al., 1975) e a Província Alcalina de Goiás (Junqueira-Brod et al., 2002). A deformação afetou toda a borda norte e nordeste da antiga Bacia do Paraná, expondo aos processos de intemperismo e erosão as rochas das formações Serra Geral ( $\mathrm{K}$ inf.), Botucatu (Jurássico), Aquidauana (P-C), bem como do embasamento pré-cambriano.

Concomitante ao soerguimento da porção norte e leste do Triângulo Mineiro (MG), a movimentação e basculamento de blocos ao longo da direção NE paralela a Sutura de Três Lagoas, bem com lineamentos de direção NW, tais como a Sutura de Itumbiara e os alinhamentos dos rios Paranapanema, Tietê e Grande, deram origem a uma nova depressão bacinal, alongada segundo a direção aproximada N-S, que se estendia do sul de Goiás até o sudoeste do estado de São Paulo, denominada Bacia Bauru (Figura 1).

O preenchimento dessa bacia teve início com a implantação de um sistema lacustre, que funcionou como nível de base para sedimentação que vinha das porções elevadas a norte e nordeste (principalmente do Soerguimento do Alto Paranaiba e a Provincia Alcalina de Goiás).

Sistemas de leques aluviais, dominados por rios (entrelaçados) adentravam a bacia gerando depósitos areno-conglomeráticos nas porções proximais (Associação 5), eventualmente retrabalhados por ventos e sujeitos aos processos pedogenéticos (Associação 4).

Depósitos fluviais entrelaçados se desenvolveram nas porções intermediárias desse sistema de leques, caracterizado por depósitos de acréscimo a jusante (DA) e depósitos de acrésci- mo lateral (LA) (Associação 3), que indicam transporte para sul (Batezelli, 2003). À medida que esses rios se distanciavam da área fonte, se tornavam mais organizados e perenes, tendendo a rios do tipo meandrante psamítico (Associação 2).

As associações de fácies, juntamente com informações petrográficas e paleontológicas (Batezelli, 2003; Batezelli et al., 2005), sugerem que o clima durante as fases de deposição do Grupo Bauru variou de úmido a árido, de acordo com Hsü (1992), Sgarbi \& Dardenne (1998) e Goldberg \& Garcia (2000). Além disso, dispunha de água suficiente para a proliferação de vida aquática (carófitos, ostracodes) e terrestre (dinossauros).

A constante atividade tectônica do Soerguimento do Alto Paranaíba (a leste e nordeste) e da Província Alcalina de Goiás (a norte) forneceu um grande aporte terrígeno para a Bacia Bauru, gerando o avanço progressivo dos depósitos aluviais sobre os depósitos lacustres.

Provavelmente, esses soerguimentos também foram os responsáveis pela criação de barreiras que impediam a circulação atmosférica no Campaniano - Maastrichtiano, conferindo um clima mais árido à região. Essa hipótese também foi aventada por Goldberg \& Garcia (2000).

Períodos de não-deposição, com retrabalhamento eólico dos sedimentos, geração de paleosolos, gretas de dissecação e formação de calcretes pedogenéticos, ocorriam em épocas mais quentes e secas.

O caráter cíclico da sedimentação, dado por pulsos, ora mais ora menos intensos das bordas norte e nordeste da Bacia Bauru, fica marcado por várias superfícies erosivas e pelo empilhamento granocrescente ascendente dos depósitos do Grupo Bauru.

A evolução do Soerguimento Alto Paranaiba e da Província Alcalina de Goiás, bem como a movimentação vertical ao longo das antigas estruturas do embasamento foram responsáveis pela circulação e concentração de águas ricas em $\mathrm{CaCO}_{3}$, favorecendo os processos de calcretização por água subterrânea que deram origem aos depósitos calcários do Membro Ponte Alta.

Com o avanço constante do sistema aluvial em direção ao nível de base, a bacia foi sendo progressivamente colmatada, até cessarem os processos sedimentares no final do Maastrichtiano. 


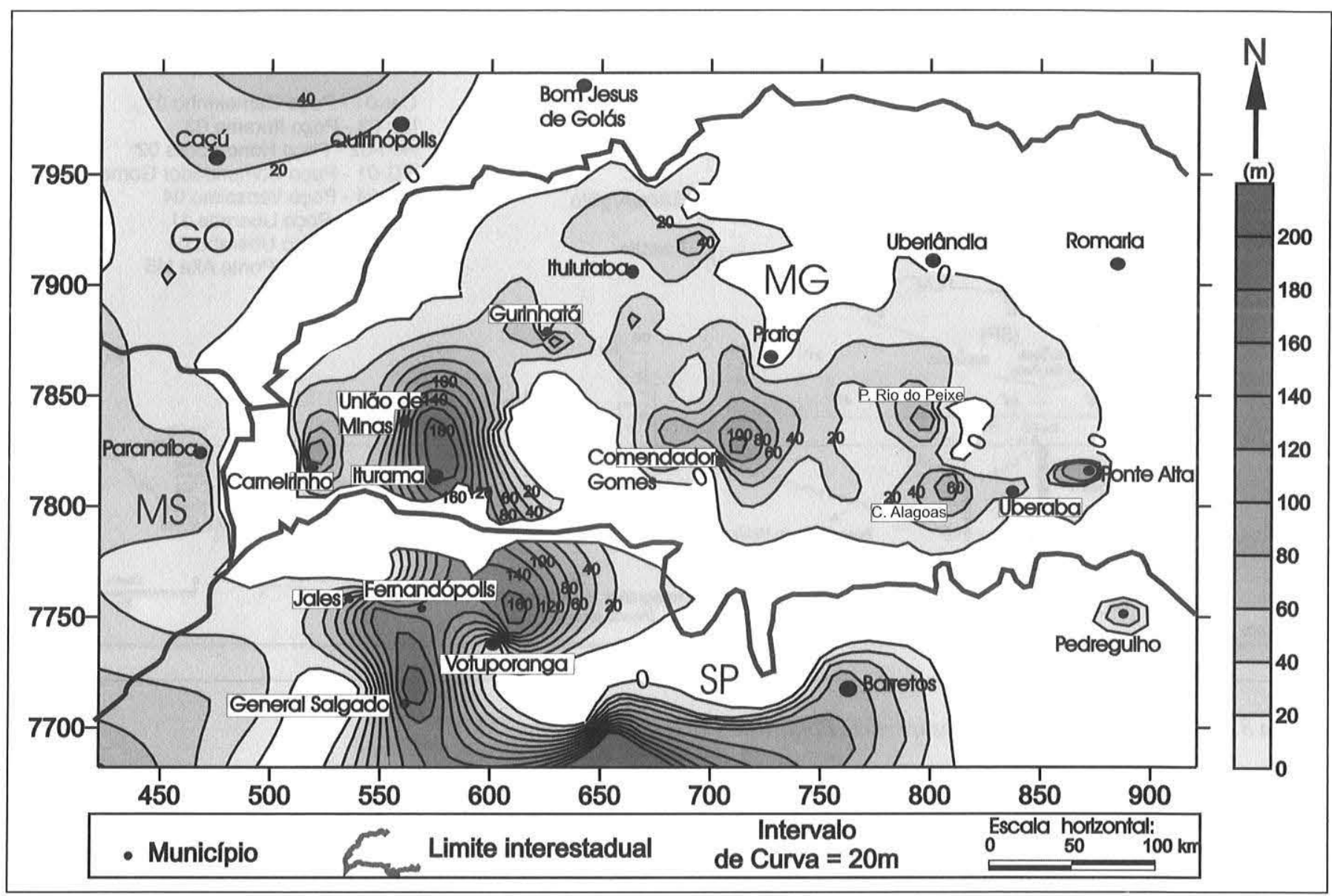

Figura 9-Mapa de isópacas do Grupo Bauru no Triângulo Mineiro e áreas Adjacentes.

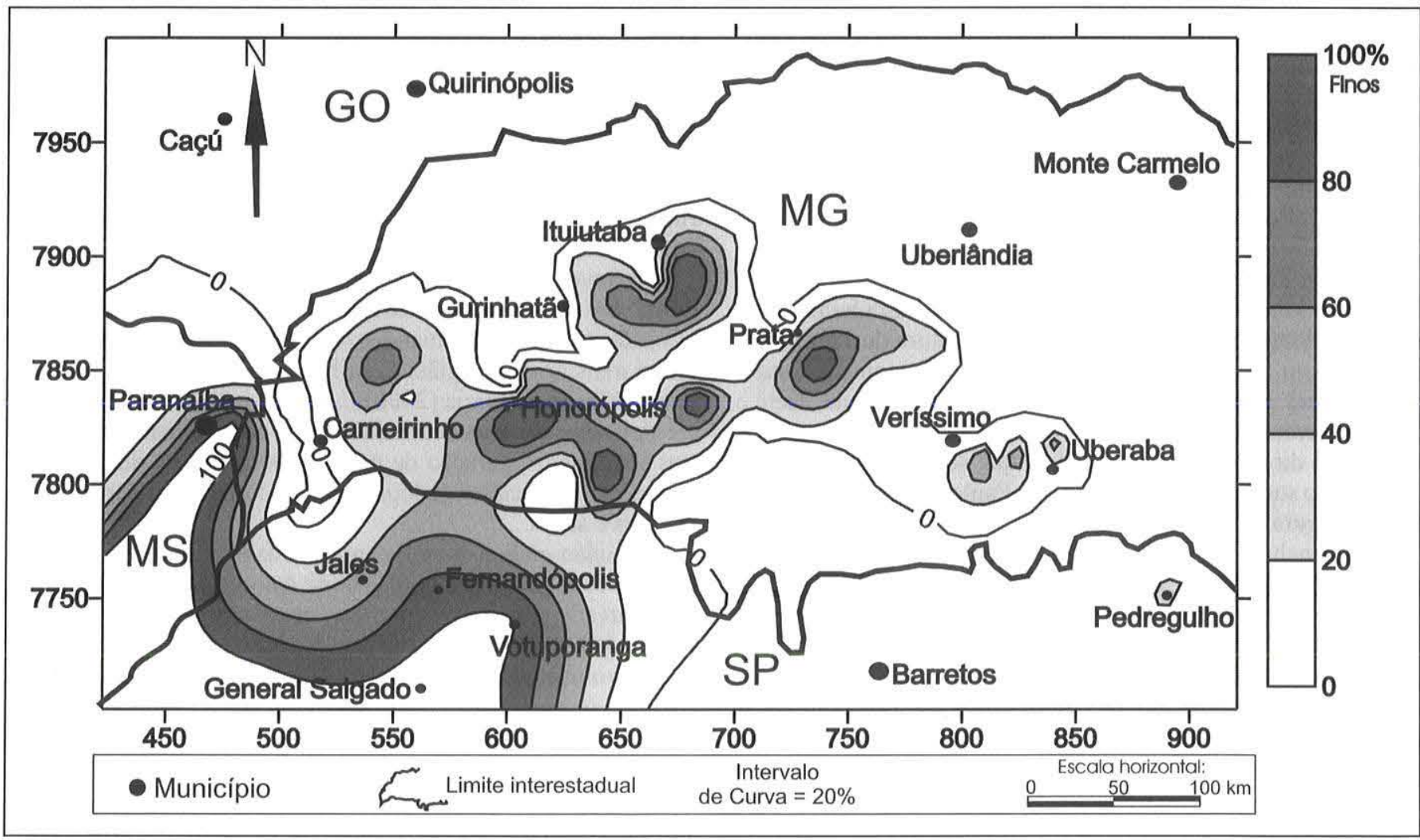

Figura 10-Mapa de isoporcentagem de fácies finas (Associação de fácies I) do Grupo Bauru no Triângulo Mineiro e áreas Adjacentes. 


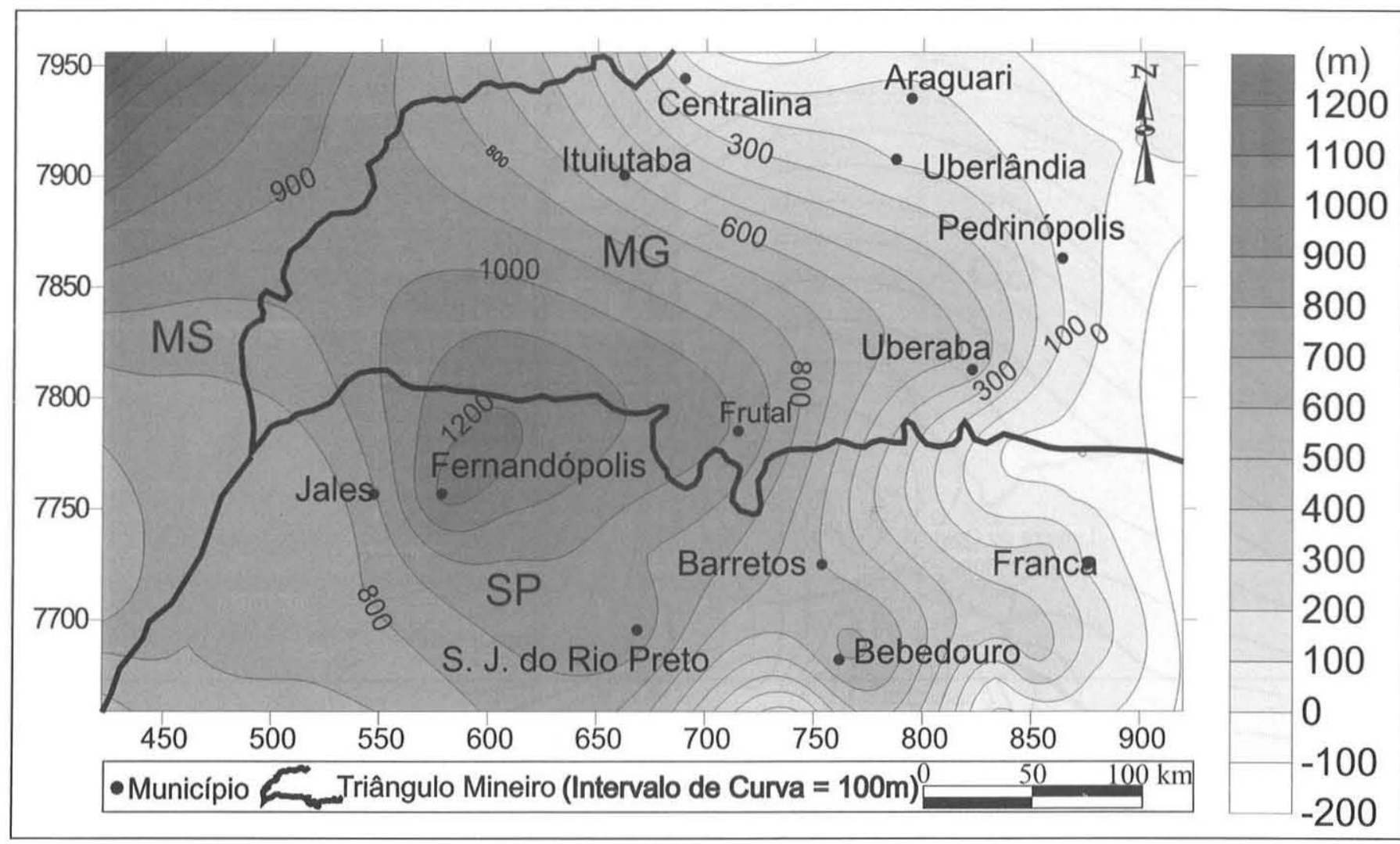

Figura 11 - Mapa de isólitas da Formação Serra Geral no Triângulo Mineiro e áreas Adjacentes.

Após algum tempo de soterramento e da atuação dos processos diagenéticos, os depósitos do Grupo Bauru no Triângulo Mineiro (MG) sofreram muitas modificações imposta por uma forte reestruturação tectônica da bacia durante o Terciário, principalmente relacionada à reativação da Sutura de Itumbiara e do Lineamento do Rio Grande, associada à tectônica Andina e aos esforços direcionais intraplaca (Neotectônica).

Responsável por uma intensa compartimentação na borda nordeste da Bacia Bauru, os eventos tectônicos terciários segmentaram a área do Triângulo Mineiro (MG) em várias depressões, onde as unidades do Grupo Bauru estão preservadas com espessuras e empilhamentos litoestratigráficos distintos (Depressões de Uberaba, Gurinhatã, Comendador Gomes, União de Minas). Esse evento tectônico também foi responsável pela elevação da porção oriental da área a cotas superiores a 700 metros (Figura 12). O modelo esquemático dessa evolução e a distribuição das áreas com maior espessura preservada das rochas do Grupo Bauru podem ser contempladas nas figuras 15 e 16.

CONCLUSÕES Baseado nas informações apresentadas conclui-se que o arcabouço estratigráfico da Bacia Bauru na região do Triângulo Mineiro e áreas adjacentes no noroeste de São Paulo, nordeste do Mato Grosso do Sul e sul de Goiás, é constituído pelas formações Adamantina (Associações 1 e 2), Uberaba (Associação 3) e Marília (Associação 4 e 5 ).

As Associações 1, 2 e 3 (formações Adamantina e Uberaba) se interdigitam lateralmente e encontram-se assentadas discordantemente sobre os basaltos da Formação Serra Geral. A exceção está no poço Itur-03, onde se encontram possivelmente assentadas sobre os arenitos do Grupo Caiuá.

A Formação Marília (Associações 4 e 5), suprajacente, é formada pelos membros Echaporã, Serra da Galga e Ponte Alta, esse último constituído essencialmente por depósitos carbonáticos, lenticulares, restritos à região de Uberaba, Uberlândia e
Monte Alegre de Minas, e alinhados segundo a direção NW, paralelos à Sutura de Itumbiara.

As fácies identificadas e descritas na área de estudo foram agrupadas em 5 associações e indicam a atuação de processos sedimentares de baixa a alta energia, relacionados a 5 ambientes deposicionais geneticamente ligados: leque proximal (Cmg, Cmm, Ceag, Cetg, Lm e Am), leque intermediário (Cmm, Ceam e Am), fluvial entrelaçado (Ceam, Am, Aea, Aet, Aeh), fluvial meandrante psamítico (Ceam, Am, Aea, Alp, Fm, Fma), lacustre (Aeag, Ar, Ao, Fm, Fma, Fs).

A ligação genética e distribuição desses ambientes são indicativas de um grande sistema de leques aluviais dominados por rios entrelaçados, gerados a partir fluxos aquosos que adentravam a bacia de nordeste para sudoeste, oriundos principalmente do Soerguimento do Alto Paranaíba (SAP) (Batezelli, 2003), em direção a um nível de base lacustre. A falta de hiato de tempo significativo entre as unidades sugere que os sistemas aluvial e lacustre coexistiram lateralmente.

As fácies que compõem a associação de fácies lacustre sugerem que o clima tenha sido mais úmido na fase inicial de sedimentação do Grupo Bauru. Já a presença de calcretes e paligorskita (Batezelli, 2003; Batezelli et al., 2005) nas rochas da Formação Marília (Associações 4 e 5), indicam incremento nas condições de aridez na fase final ou pós-deposicional da sedimentação cretácea.

Além dos corpos alcalinos e rochas metamórficas que serviram de fonte de sedimentos, o soerguimento imposto pela passagem da pluma mantélica de Trindade (Gibson et al., 1995) alçou as camadas juro-cretáceas (formações Botucatu e Serra Geral), propiciando sua erosão e fornecendo suprimento terrígeno para o preenchimento da Bacia Bauru, sobretudo na geração dos depósitos da Formação Uberaba.

Na borda norte da Bacia Bauru (região de Caçú e Quirinópolis - GO), o predomínio de sedimentos oriundos da erosão de 


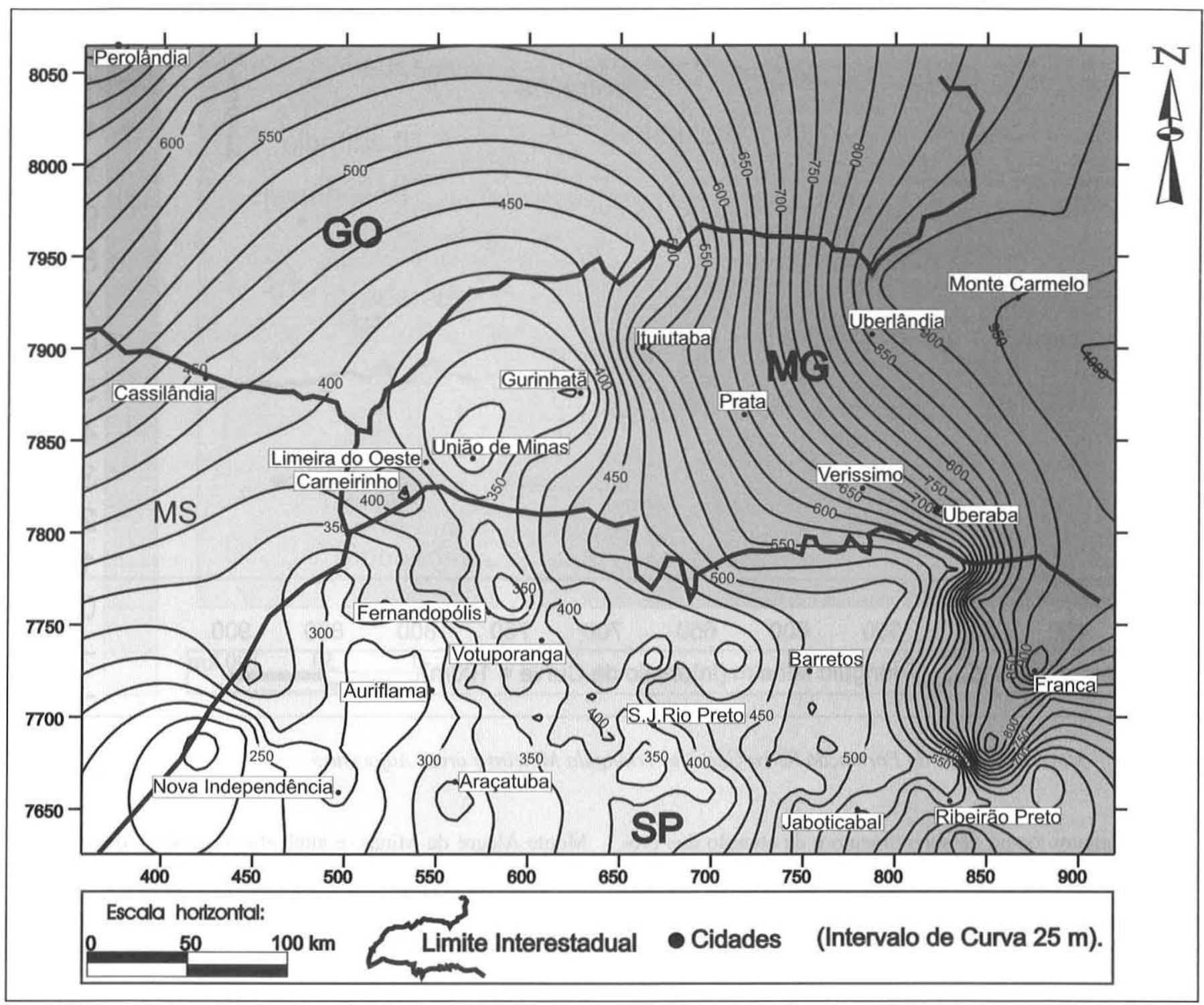

Figura 12 - Mapa de Contorno Estrutural do Topo da Formação Serra Geral no Triângulo Mineiro e áreas Adjacentes.

rochas paleozóicas da Bacia do Paraná, fragmentos de quartzo, quartzito, basalto e vulcânicas alcalinas, bem como dados de paleocorrentes (Batezelli, 2003), sugerem que a principal áreafonte dessa porção tenha sido a Província Alcalina de Goiás (PAGO).

O eixo deposicional da Bacia Bauru de direção N-S, certamente foi controlado por estruturas antigas do embasamento, reativadas durante o Cretáceo Superior (Alinhamentos de Três Lagoas, Presidente Prudente e Ribeirão Preto - Hasui et al., 1989).

Um nível de base lacustre se desenvolveu segundo essa direção, na área hoje balizada pelas cidades de Miraporanga (MG), Ituiutaba (MG), Limeira D'Oeste (MG), Iturama (MG) e Fernandópolis (SP), se estendendo pela parte ocidental do estado de São Paulo. Dessa forma, os depósitos lacustres da Formação Adamantina no Triângulo Mineiro são correlacionados aos depósitos lacustres da Formação Araçatuba, no Estado de São Paulo.

Esse lago foi palco de sedimentação fina, constituída basicamente pelas Associações 1 e 2 .

A presença de níveis lamíticos na porção basal da Formação Uberaba, constatado através dos dados de subsuperfície, pode ser indício de que o limite do sistema lacustre (nível de base) tenha sido maior durante os primeiros estágios da Bacia Bauru.

O sistema aluvial, formado pelas Associações 3, 4 e 5, so- brepujou progressivamente os depósitos lacustres distais, como resposta aos constantes pulsos de rejuvenescimento da área fonte situada na borda norte e nordeste da Bacia Bauru. Essa característica é marcada pelo empilhamento granocrescente ascendente das associações de fácies.

Por fim, com o término da sedimentação, a Bacia Bauru passou por um processo de reestruturação durante o Terciário. A reativação tectônica cenozóica que assolou a porção nordeste da bacia, principalmente a movimentação ao longo da Sutura de Itumbiara e Lineamento do Rio Grande, causou a desarticulação dos depósitos do Grupo Bauru, preservando-os distintamente nas depressões de Uberaba, Gurinhatã, Comendador Gomes, União de Minas, conforme observado nas seções e mapas estratigráficos.

$\mathrm{O}$ fato de que a faixa de afloramentos do Membro Ponte Alta (fácies Lm) esteja alinhada na direção NW, é um forte indício de que o processo de calcretização mais intenso na Bacia Bauru tenha sido condicionado por reativações da Sutura de Itumbiara.

Após o ciclo deposicional que deu origem às rochas do Grupo Bauru, a reativação desse lineamento causou uma reestruturação na borda NE da Bacia Bauru, dando origem às depressões de Uberaba e Gurinhatã, separadas por um alto na região de Veríssimo (MG). Na depressão gerada a leste desse alto (Depressão de 


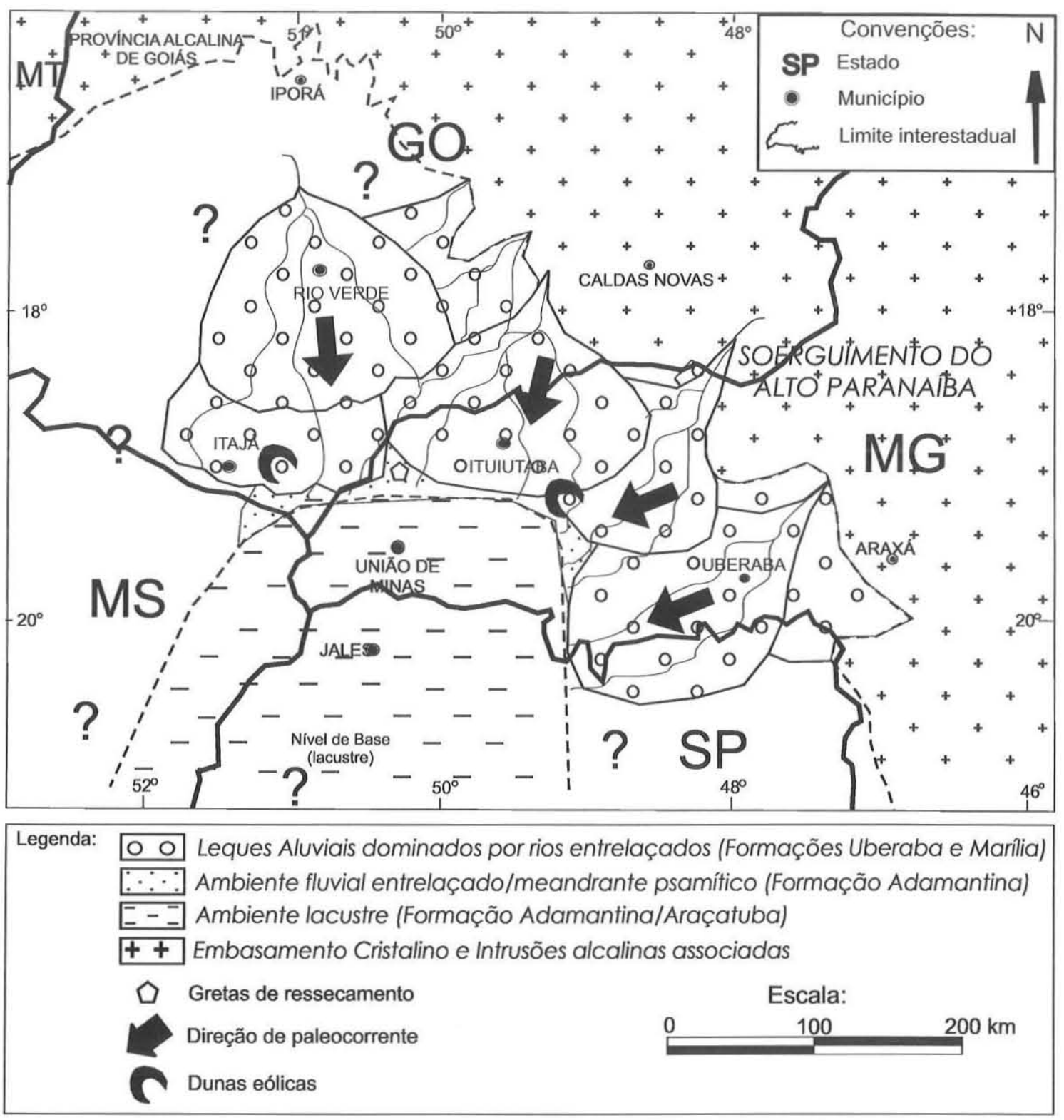

Figura 13 - Distribuição paleogeográfica dos ambientes que coexistiam na fase inicial de sedimentação da Bacia Bauru (Batezelli, 2003).

Uberaba) o lençol freático ficou barrado. A elevação do nível freático associado ao clima árido/semi-árido propiciou a concentração e precipitação do $\mathrm{CaCO}_{3}$. Em maior ou menor proporção de acordo com as condições de permo-porosidade dos depósitos.

Para a porção oeste do Triângulo Mineiro (Depressão de Gurinhatã), as condições hidrogeológicas favoreceram uma calcretização menos intensa (do tipo pedogenético), não formando depósitos economicamente exploráveis. A interpretação dos dados apresentados permite propor que o modelo de formação dos calcretes seja semelhante ao proposto por Silva et al. (1994), discordando do ponto de vista da idade de sua gênese, admitida por aqueles autores como sendo penecontemporânea ao Grupo Bauru.

Agradecimentos: A Fundação de Amparo à Pesquisa do Estado de São Paulo - FAPESP pelo apoio financeiro aos projetos 99/00324-1e 99/00323-5. Aos professores doutores Antonio Roberto Saad (UNESP - Rio Claro), Márcia Ernesto (IAG-USP - São Paulo), Vicente José Fulfaro (UNESP - Rio Claro), José Alexandre de Jesus Perinotto (UNESP - Rio Claro), Paulo Milton Barbosa Landim (UNESP - Rio Claro), pelas importantes discussões no decorrer da pesquisa. Aos relatores pelas críticas e sugestões. 


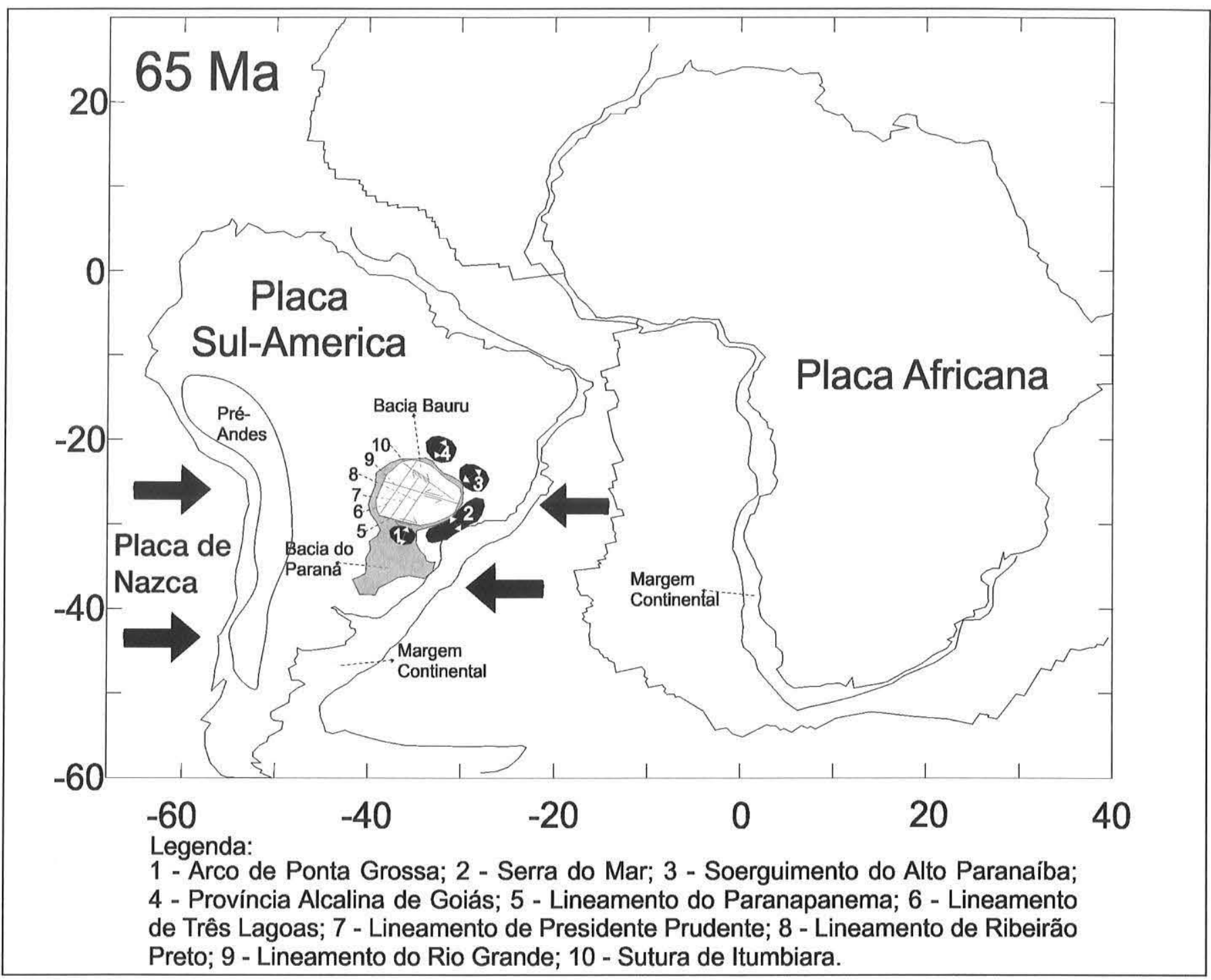

Figura 14 - Bacia Bauru e a Paleogeografia da América da América do Sul durante o Cretáceo Superior.

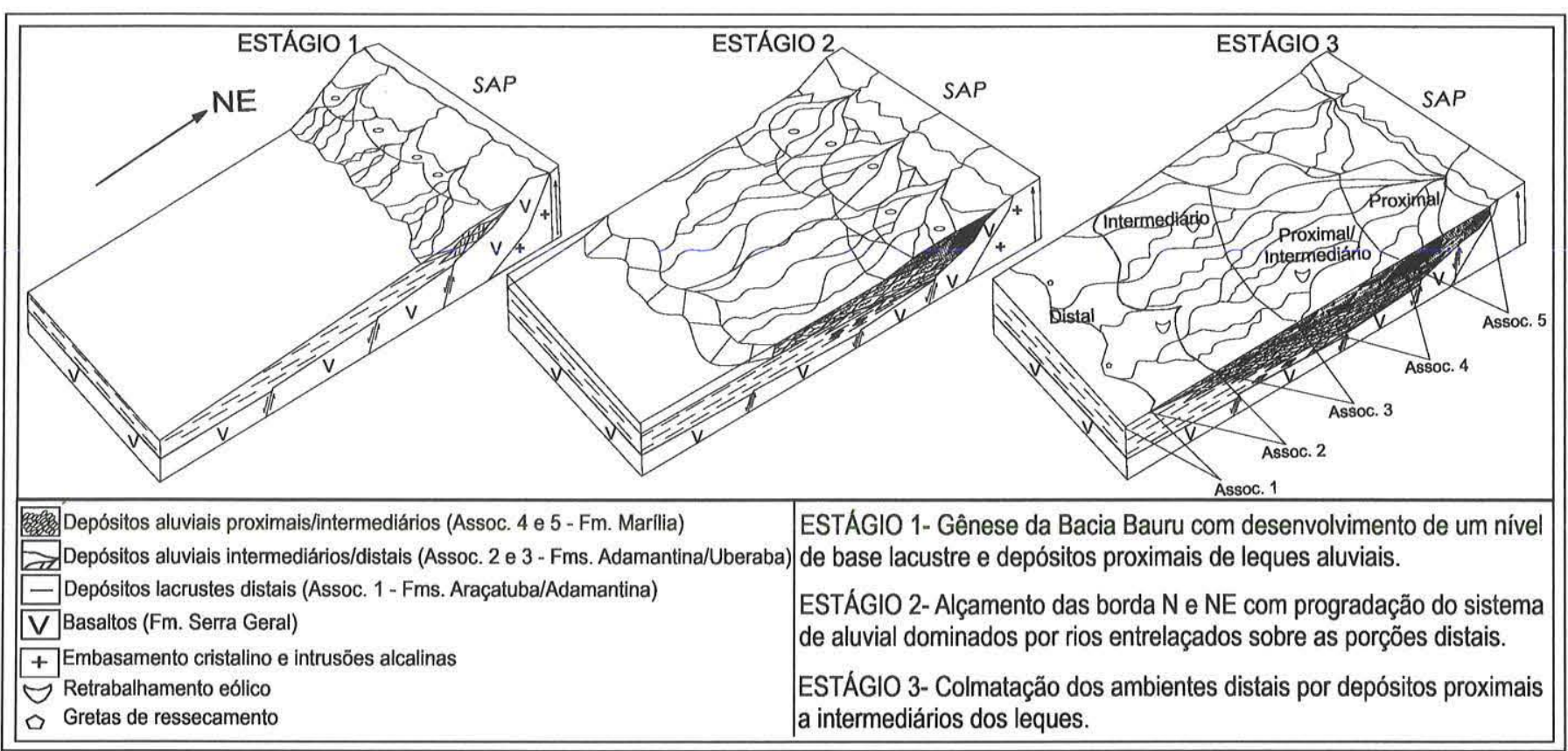

Figura 15 - Modelo esquemático mostrando a evolução tectono-estratigráfica porção norte e nordeste da Bacia Bauru 


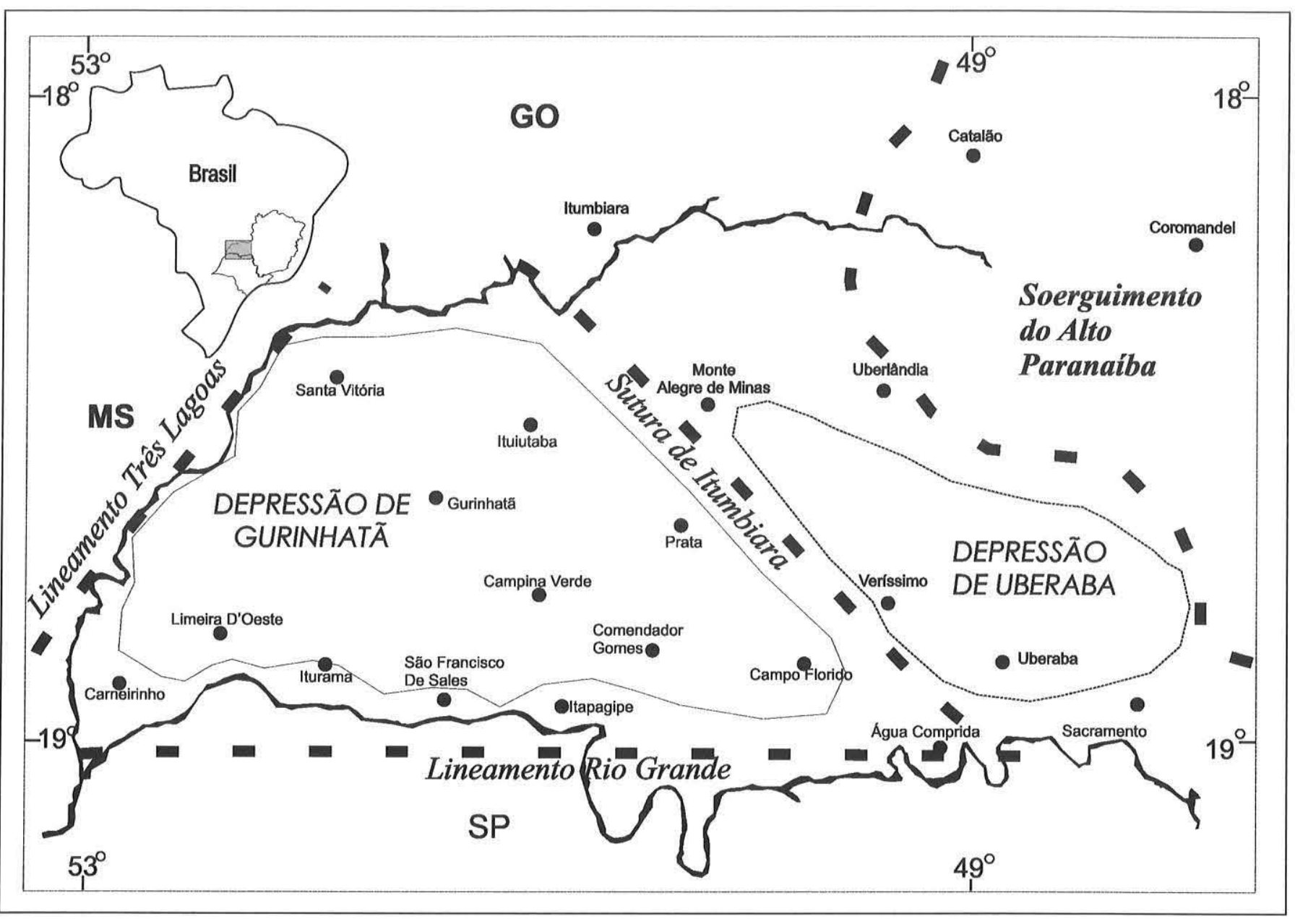

Figura 16 - Mapa das depressões de Uberaba e Gurinhatã, na porção NE da Bacia Bauru.

\section{Referências}

Almeida F.F.M. de. 1983. Relação tectônica das rochas alcalinas Mesozóicas da região meridional da Plataforma Sulamericana. Revista Brasileira de Geociências, 13(3):139-158.

Almeida F.F.M. de. 1986. Distribuição regional e relações tectônicas do magmatismo pós-Paleozóico no Brasil. Revista Brasileira de Geociências, 16(4):325-349.

Alves J.M.P. 1995. Petrologia e diagênese do Membro Ponte Alta, Formação Marilia, Cretáceo da Bacia do Paraná, na região do Triângulo Mineiro. Dissertação de Mestrado, Universidade Federal de Ouro Preto-MG, 102 p.

Barbosa O., Braun O.P.G., Dyer R.C., Cunha C.A.B.R. 1970. Geologia da região do Triângulo Mineiro. Rio de Janeiro, DNPM/DFMP, Boletim 136

Barcelos J.H. 1984. Reconstrução paleogeográfica da sedimentação do Grupo Bauru baseada na sua redefinição estratigráfica parcial em território Paulista e no estudo preliminar fora do Estado de São Paulo. Tese de Livre Docência, Instituto de Geociências e Ciências Exatas, Universidade Estadual Paulista, Rio Claro-SP, 190p.

Batezelli A. 1998. Redefinição litoestratigráfica da Unidade Araçatuba e da sua extensão regional na Bacia Bauru no Estado de São Paulo. Dissertação de Mestrado, Instituto de Geociências e Ciências Exatas, Universidade Estadual Paulista, Rio Claro-SP, 110 p.

Batezelli A., 2003. Análise da Sedimentação Cretácea no Triângulo Mineiro e sua Correlação com Áreas Adjacentes. Tese de Doutoramento, Instituto de Geociências e Ciências Exatas, Universidade Estadual Paulista, Rio Claro-SP, 183p.

Batezelli A., Saad A. R., Etchebehere M. L. de C., Perinotto J. A. de J., Fulfaro V. J. 2003. Análise Estratigráfica Aplicada á Formação
Araçatuba (Grupo Bauru - Ks) No Centro-Oeste do Estado de São Paulo. Geociências, 22:05-19.

Batezelli A., Gomes N. S., Perinotto J. A. de J. 2005. Petrografia e evolução diagenética dos arenitos da porção norte e nordeste da Bacia Bauru (Cretáceo Superior). Revista Brasileira de Geociências, 35(3): 311-322.

Coimbra A. M. 1991. Sistematização Crítica da Obra. Tese de Livredocência, Instituto de Geociências da Universidade de São Paulo São Paulo, 54 p.

Coimbra A. M., Brandt Neto M., Coutinho J. M. V. 1981. Silicificação dos Arenitos da Formação Bauru no Estado de são Paulo. In: SBG, A Formação Bauru no Estado de São Paulo e regiões adjacentes, São Paulo. Coletânea de trabalhos e debates, p. 103-115.

Danni J. C. M. 1996. Evolução Tectono-Magmática da Província Alcalina do Sul de Goiás. In: SBG, Simpósio Sobre o Cretáceo do Brasil, 4, Atas, p. 235-237.

Dias-Brito D., Musacchio E. A., Castro J. C., Maranhão M. S. A. S., Suárez J. M., Rodrigues R. 2001. Grupo Bauru: uma unidade continental Cretácea no Brasil - concepções baseadas em dados micropaleontológicos, isotópicos e estratigráficos - Revue Paléobiologic, 20(1):245-304.

Etchebehere M. L. de C., Silva R. B. da, Saad A. R., Resende A. C. de. 1993. Reavaliação do potencial do Grupo Bauru para evaporitos e salmouras continentais. Geociências, 12:333-352.

Fernandes L. A. 1992. A cobertura Cretácea Suprabasaltica no Estado do Paraná e Pontal do Paranapanema (SP): Os Grupos Bauru e Caiuá. Dissertação de Mestrado, Instituto de Geociências, Universidade de São Paulo, São Paulo, 171p. 
Fernandes L. A. 1998. Estratigrafia e evolução geológica da parte oriental da Bacia Bauru (Ks, Brasil). Tese de Doutorado, Instituto de Geociências, Universidade de São Paulo, São Paulo, 216p.

Fernandes L. A. \& Coimbra A. M. 1996. A Bacia Bauru (Cretáceo Superior, Brasil) - Anais da Academia Brasileira de Ciências, 68(2): 195-205.

Fernandes L. A. \& Coimbra A. M. 2000. Revisão estratigráfica da parte oriental da Bacia Bauru (Neocretáceo) Revista Brasileira de Geociências, 30(4):717-728.

Ferreira Jr. P. D. 1996. Modelo deposicional e evolução diagenética da Formação Uberaba, Cretáceo Superior da Bacia do Paraná, na região do Triângulo Mineiro. Dissertação de Mestrado, Universidade Federal de Ouro Preto, Ouro Preto-MG, 175p.

Fulfaro V. J. 1974. Tectônica do Alinhamento Estrutural do Paranapanema. Boletim do IG (Instituto de Geociências - USP), 5:129-138.

Fulfaro V. J., Perinotto J. A. de J. 1996. A Bacia Bauru: Estado da Arte. In: SBG, Simpósio sobre o Cretáceo do Brasil, 4, Atas, p. 297 303.

Fulfaro V. J., Perinotto J. A. J., Barcelos J. H. 1994. A Margem Goiana do Grupo Bauru: implicações na litoestratigrafia e paleogeografia. In: SBG, Simpósio Sobre o Cretáceo do Brasil, 3, Atas, p. 81-84.

Fulfaro V. J., Etchebehere M. L. de C., Perinotto J. A. J., Saad A. R. 1999. Bacia Caiuá: uma nova bacia Cretácea na Bacia do Paraná. In: SBG, Simpósio sobre o Cretáceo do Brasil, 5, Simposio Sobre El Cretacico de América del Sur, 1, Atas, p. 439-442.

Gibson S. A., Thompson R. N., Leonardos O. H., Dickin A. P., Mitchell J. G. 1995. The late Cretaceous impact of the Trindade Mantle Plume: evidence from large volume, mafic, potassic magmatism in SE Brazil. Journal of Petrology, 36(1):189-229.

Galloway W. E. \& Hobday D. K. 1983.Terrigenous clastic depositional systems - applications to petroleum, coal, and uranium exploration. Springer-Verlag, New York, $423 \mathrm{p}$.

Goldberg K. 1995. Reconstituição paleoambiental do Cretáceo continental brasileiro na região do Triângulo Mineiro. Dissertação de Mestrado, Universidade do Vale do Rio dos Sinos, São LeopoldoRS, $181 \mathrm{p}$.

Goldberg K. \& Garcia A. J. V. 2000. Paleobiogeography of the Bauru Group. A dinossaur-bearing Cretaceous unit, northeastern Paraná Basin, Brazil. Cretaceous Research, 21:241-254.

Gonzaga de Campos L. F. 1905. Reconhecimento da região compreendida entre Bauru e Itapura (estrada de ferro noroeste do Brasil). Tip. Ideal, São Paulo, 40 p.

Hasui Y. 1967. Geologia das Formações Cretáceas do oeste de Minas Gerais. Tese de Doutoramento, Escola Politécnica da Universidade de São Paulo, São Paulo, 95p.

Hasui Y. \& Haralyi N.L.E.,1991. Aspectos Lito-estruturais e geofisicos do soerguimento do Alto Paranaíba. Geociências, 10:67-77.

Hasui Y., Sadowski G.R., Suguio K., Fuck G.F. 1975. The Phanerozoic Tectonic Evolution of the Western Minas Gerais State. Anais Academia Brasileira de Ciências, 47(314):431-438.

Hasui Y., Haralyi N. L. E., Miotto J. A., Saad A. R., Campanha V.A., Hanza V. M., Frangipani A., Puleghini F. P. (Coords.), 1989. Compartimentação Estrutural e Evolução Tectônica do Estado de São Paulo. São Paulo 2v. IPT, (Relatório 27.394), 210p.

Hsü K. J. 1992. Is Gaia Endothermic? Geol. Mag., 129(2):129-141.

Junqueira-Brod T. C., Roig H. L., Gaspar J. C., Brod J. A., Meneses P. R. 2002. A Província Alcalina de Goiás e a extensão do seu vulca- nismo kamafugítico. Revista Brasileira de Geociências, 32(4):559566.

Miall A. D. 1985. Architectural-element analysis: a new method of facies analysis applied to fluvial deposits. Earth Science Reviws, 22(4):261-300.

Ribeiro D. T. P. 1997. Diagênese e petrografia das rochas do Membro Serra da Galga, Formação Marilia, Grupo Bauru (Cretáceo da Bacia do Paraná), na região de Uberaba, MG. Dissertação de Mestrado, Universidades Federal de Ouro Preto, Ouro Preto-MG, $108 \mathrm{p}$.

Renne P. R. 1997. Geochronology of the Paraná-Etendeka Igneous Province. In: SBG, South America Symposium on Isotope Geology, Atas, p. 20-23.

Riccomini C. 1995. Tectonismo gerador e deformador dos depósitos sedimentares pós-Gondwânicos da porção centro-oriental do Estado de São Paulo e áreas vizinhas. Tese de Livre-Docência, Instituto de Geociências da Universidade de São Paulo, São Paulo-SP, 100 p.

Santucci R. M. \& Bertini R. J., 2001. Distribuição paleogeográfica e biocronológica dos Titanossauros (Saurish, Sauropoda) do Grupo Bauru, Cretáceo Superior do sudeste brasileiro. Revista Brasileira de Geociências, 31(3):307-315.

Sgarbi G. N. C. \& Dardenne M. A. 1998. Evolução climática do Gondwana nas regiões centro-sul do Brasil e seus registros geológicos continentais durante o Mesozóico, enfatizando o Arco do Alto Paranaíba, a borda NNE da Bacia do Paraná e a porção meridional da Bacia Sanfranciscana, no oeste do Estado de Minas Gerais. Geonomos, 4(1):21-49.

Silva R. B. de, Etchebehere M. L. de C., Saad A. R. 1994. Groundwater calcretes: uma interpretação alternativa para os calcários da Formação Marília no Triângulo Mineiro. In: SBG, Simpósio sobre o Cretáceo do Brasil, 3, Atas, p. 85-90.

Soares P. C. \& Landim P. M. B. 1975. Comparison between the tectonic evolution of the intracratonic and marginal basins in south Brazil Anais da Academia Brasileira de Ciências, 48(Suplemento):313324.

Soares P. C., Landim P. M. B., Fulfaro V. J., Sobreiro Neto A. F. 1980. Ensaio de caracterização estratigráfica do Cretáceo no Estado de São Paulo: Grupo Bauru. Revista Brasileira de Geociências, 10(3):177-185.

Suguio K. 1980. Fatores paleoambientais e paleoclimáticos, e subdivisão estratigráfica do Grupo Bauru - In: SBG, Mesa Redonda: A Formação Bauru no Estado de São Paulo e regiões adjacentes. Coletânea de trabalhos e debates, São Paulo, Atas, p. 15-30 (Publicação Especial, 7).

Suguio K., Fulfaro V. J., Amaral G., Guidorzi L. A. 1977. Comportamentos estratigráfico e estrutural da Formação Bauru nas regiões administrativas 7 (Bauru), 8 (São José do Rio Preto) e 9 (Araçatuba) no Estado de São Paulo. In: SBG, Simpósio Regional de Geologia, 1, Atas, 2:231-247.

Washburne C. W. 1930. Petroleum geology of the State of São Paulo, Brasil. Bol. Com. Geogr: e Geol. (São Paulo), 22:1-282. In: J. Pacheco (1939 - tradução). Geologia do Petróleo no Estado de São Paulo. DNPM, Rio de Janeiro, 228p.

Manuscrito A-1577

Revisão aceita em 14 de junho de 2006 